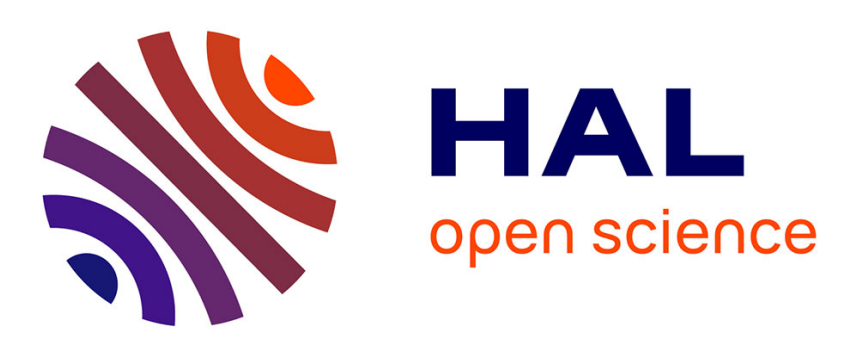

\title{
A new onychodont (Osteichthyes; Sarcopterygii) from the Middle Devonian of Morocco and its bearing on early osteichthyan evolution
}

Jorge Mondéjar-Fernández

\section{- To cite this version:}

Jorge Mondéjar-Fernández. A new onychodont (Osteichthyes; Sarcopterygii) from the Middle Devonian of Morocco and its bearing on early osteichthyan evolution. Journal of Systematic Palaeontology, 2020, 18 (7), pp.573-606. 10.1080/14772019.2019.1655495 . mnhn-02976939

\section{HAL Id: mnhn-02976939}

\section{https://hal-mnhn.archives-ouvertes.fr/mnhn-02976939}

Submitted on 10 Nov 2020

HAL is a multi-disciplinary open access archive for the deposit and dissemination of scientific research documents, whether they are published or not. The documents may come from teaching and research institutions in France or abroad, or from public or private research centers.
L'archive ouverte pluridisciplinaire HAL, est destinée au dépôt et à la diffusion de documents scientifiques de niveau recherche, publiés ou non, émanant des établissements d'enseignement et de recherche français ou étrangers, des laboratoires publics ou privés. 
A new onychodont (Osteichthyes; Sarcopterygii) from the Middle Devonian of Morocco and its bearing on early osteichthyan evolution

Jorge Mondéjar-Fernández*

ISYEB, UMR 7205 CNRS-MNHN-UPMC-EPHE, Département Origines et Évolution

Muséum National d'Histoire Naturelle, Sorbonne Université, CP 30, 25 rue Cuvier, 75005

Paris, France

*Corresponding author. E-mail: jorge.mondejar-fernandez@mnhn.fr 


\section{ABSTRACT}

A new onychodont sarcopterygian is described from the Middle Devonian (Eifelian) of Morocco. Selenodus aquesbiae gen. et sp. nov is characterized by a unique suite of traits among onychodonts such as a large maxilla with a rounded posterior expansion and a straight ventral margin, the presence of a single supraorbital, and a reduced opercular series. It also displays certain features commonly found in onychodontids and early sarcopterygians, like a lateral rostral contacting the orbit through a narrow postero-dorsal projection, numerous sclerotic plates surrounding the orbit, the occurrence of an accessory row of small denticles labially lining the single row of teeth from the upper and lower jaws, a prearticular ornamented with small rounded tubercules, the postotic lateral line canal passing through the supratemporal, tabular and lateral extrascapular bones of the skull roof, and dermal bones and rounded scales ornamented by small dentine tubercules capped with enamel. All the fossil remains belong to a single individual representing a relatively large fish (around 1 meter of estimated length based on the skull dimensions) for which the snout, cheek, and skull roof have been partially reconstructed. The well-preserved material comprises mainly the dermocranium but two branchial elements are known, adding to our knowledge of early osteichthyan endoskeleton. A phylogenetic analysis places Selenodus in an unresolved polytomy among onychodonts and coelacanths, enabling to discuss evolutionary scenarios and character combinations among early osteichthyans. The close relationship between onychodonts and actinistians is firmly established and hints towards the consideration of all onychodont taxa as stem coelacanths. Selenodus represents the first occurrence of onychodonts from Africa and furnishes key information not only on onychodont morphology and interrelationships but also on their paleobiogeographical distribution and Devonian faunal affinities between Euramerica and Gondwana.

Keywords: Devonian, Gondwana, histology, Onychodontida, phylogeny, stem-coelacanth 


\section{INTRODUCTION}

The Onychodontida ("Struniiformes" or Onychodontiformes) stand among the earliest lineages of sarcopterygians (lobe-finned fishes) but still remain one of the most enigmatic groups of early osteichthyans (bony fishes) (e.g., Andrews 1973; Janvier 1996; Long 2011). Onychodonts were marine, eel-like predatory fishes of variable size occurring worldwide from the Early Devonian (Pragian) to the Late Devonian (Famennian), characterized by a distinctive head morphology including large parasymphysial tooth whorls with sigmoid tusks on their lower jaws associated with internasal pits on the ethmoid floor, the absence of cosmine covering on the dermoskeleton, rounded scales ornamented with pointy tubercules, and a strongly developed striation pattern of the enamel in the tusks. They are currently represented by six genera: Onychodus Newberry 1857; Strunius Jessen 1966; Grossius Schultze 1973; Lukeus Young \& Schultze 2005; Bukkanodus Johanson et al. 2007 and Qingmenodus Lu \& Zhu 2010.

It is widely recognized that the onychodonts represent a monophyletic group (e.g., Cloutier \& Ahlberg 1996; Janvier 1996; Campbell \& Barwick 2006, Lu et al. 2016a; contra Friedman 2007). However, their affinities within the Sarcopterygii are still a matter of debate. Several phylogenetic scenarios have been considered: 1) sister to the crown group Sarcopterygii (Friedman 2007); 2) as a plesion closely related to Psarolepis (Janvier 1996; Long 2001; Jeffery 2012); 3) sister to the rhipidistians (i.e., dipnomorphs and tetrapodomorphs) (Cloutier \& Ahlberg 1995, 1996) or to the rhipidistians excluding dipnoans (Schultze 1987; Long 1989; Young et al. 1992); and 4) sister group of the actinistians in an unnamed clade (Cloutier \& Ahlberg 1995; Zhu \& Schultze 1997, 2001; Zhu et al. 1999, 2001, 2006, 2009; Botella et al. 2007). This last scenario is supported by most recent analyses (Lu \& Zhu 2010; Lu et al. 2016a,b, 2017; Clement et al. 2018).

Our knowledge on onychodont morphology is mostly based on disarticulated fragmentary dermal skull material, the endoskeleton being poorly known. Grossius, represented by a single species $G$. aragonensis, is known from a single specimen of a large three-dimensional skull from the Frasnian of Spain (Schultze 1973). Strunius is known from well-preserved, although flattened, cranial material and complete bodies from the Frasnian of Germany (Upper Plattenkalk, Bergisch Gladbach). Although usually considered as a juvenile onychodont (e.g., Thomson \& Hahn 1968), Jessen (1966) described two species: S. walteri and S. rolandi (formerly attributed to Onychodus by Gross 1956). Further remains of Strunius 
sp. are also known from the Baltic States (Gross 1956; Jessen 1966, Upeniece 1995), Iran (Janvier \& Martin 1979), and China (Zhu \& Janvier 1994). The Emsian-Eifelian Luckeus abudda from Australia is solely known by an isolated left lower jaw and associated teeth (Young \& Schultze 2005). The recently described Qingmenodus is represented by a single species, Q. yui from the Pragian of China (Lu \& Zhu 2010). The material consists of threedimensionally preserved skulls, comprising both portions of the neurocranium that have furnished key information on the braincase anatomy and evolution of onychodonts and sarcopterygians (Lu et al. 2016a).

Onychodus is undoubtedly the best-known and most widely found onychodont. Remains attributed to Onychodus are known from North America (Newberry 1857, 1873, 1889; Hussakof \& Bryant 1918; Jessen, 1966; Turner \& Murphy 1988; Mann et al. 2017), Australia (Ørvig 1969; Giffin 1980; Turner 1993; de Pomeroy 1995, 1996; Turner et al. 2000; Lindley 2002; Andrews et al. 2006), Europe (Gross 1933, 1956, 1965; Jessen 1966; Otto 1999), and the Middle East (Janvier \& Martin 1979; Blieck et al. 1980). The genus Onychodus currently comprises five well-defined species: O. sigmoides Newberry 1857, O. jaeckeli Gross 1965, O. obliquedentatus Jessen 1966, O. jandemarrai Andrews et al. 2006, and O.eriensis Mann et al. 2017. Other putative species of Onychodus include O.anglicus Woodward 1888, O. articus Woodward 1889, O. hopkinsi Newberry 1889, O. ortoni Newberry 1889, O. firouzi Janvier and Martin 1979, and O. yassensis Lindley 2002. However, these forms are known from isolated teeth, scales, and bone fragments and therefore their status as reliable species is doubtful. The almost perfectly preserved cranial and post-cranial material of $O$. jandemarrai from the lower Frasnian Gogo Formation of Australia (Andrews 1973; Long 1991; Andrews et al. 2006) has set the landmark for all subsequent morphological descriptions of onychodont remains.

Onychodonts are exclusively bound to the Devonian period. The earliest occurrences from the Early Devonian include a lower jaw fragment reminiscent of Strunius from the Pragian of China (Zhu \& Janvier 1994), which probably belongs to Qingmenodus (Lu \& Zhu 2010). An incomplete cosmine-bearing dentary from the Lochkovian of China (Zhu \& Yu 2004) has been tentatively assigned to the Onychodontida, thus implying that the oldest onychodonts might have been covered with cosmine (Mondéjar-Fernández 2018). The oldest onychodont is Bukkanodus jesseni known from disarticulated skull material and scales from the Pragian of Australia (Johanson et al. 2007), which has been considered the sister taxon of 
other onychodonts (Lu \& Zhu 2010) or to the clade of actinistians and onychodonts (Lu et al. 2016a).

Herein, a new species of onychodont from the Middle Devonian of Morocco is redescribed. It represents their first occurrence in Africa and one of the earliest onychodonts known from articulated remains. Its attribution to the Onychodontida is based on the snout and cheek bones pattern, the absence of cosmine and the characteristic ornamentation of the dermal bones and scales. The remains are mostly composed of dermal bones on which the course of the lateral line can be traced through direct and X-ray-based observation; two wellpreserved endoskeletal elements of the branchial arches are also known. The material was formerly studied by Lehman (1976) and Aquesbi (1988) but neither of them erected a proper name to this new form. Given the recent advance in our knowledge on onychodont cranial morphology (Andrews et al. 2006; Johanson et al. 2007; Lu et al. 2010, 2016a), we can now undisputedly assign the Moroccan specimen to a new genus and species within the Onychodontida and discuss its implications in early osteichthyan evolutionary history.

\section{GEOLOGICAL SETTING}

The material was collected in 1966 in the Devonian outcrops from the Akka valley, Tindouf bassin, Southern Morocco (Fig. 1). Devonian rocks are exposed as parallel strips with WS-EN direction between the town of Akka and the Dra oued (Fig. 1A-B). The geology and stratigraphy of the Tindouf bassin has been well documented by Hollard (e.g., 1974, 1977, 1981) and vertebrate remains from these localities were formerly described by Lehman (1976) and reviewed by Lelièvre (1984). These include placoderms (isolated and/or articulated bony plates of ?Eastmanosteus sp., Actinosteus lehmani former Tityosteus sp., and Hollardosteus), chondrichthyans (putative Ctenacanthus spines), acanthodians (Machaeracanthus spines), and the herein redescribed onychodont. All fossil remains come from greatly eroded calcareous concretions or nodules attributed by Hollard (1977) to the brachiopod Acrospirifer speciosus limestones levels and thus would be late Eifelian (Middle Devonian) in age (Becker et al. 2004). Hollard (1978) interpreted the Dra outcrops as representing a marine coastal coral reef setting. Paleogeographical reconstructions of Southern Morocco during the Middle Devonian (e.g., Golonka, 2000; Scotese, 2001) situate the locality in sub-tropical latitudes of the southern paleohemisphere at the Northern margin of Central Gondwana (Fig. 1C). 


\section{MATERIAL AND METHODS}

\section{Material}

The material consists of fragments of endoskeletal and dermal bones, teeth and scales from several scattered calcareous concretions. Given the ornamentation consistency and relative size of the bones it is assumed that all fossil specimens belong to a single individual. Many dermal bones, which are extremely fragile, are exposed in the surface or preserved as imprints in the calcareous and strongly altered matrix. The endoskeletal bones are hollow and filled with sediment, suggesting that their inner portion was weakly ossified. Most of the bones belong to the left side of the animal (snout, cheek and skull roof) but certain large fragments (upper and lower jaws, branchial arches) come from the right side (Fig. 2). Many cranial dermal bones have retained their original margins and articulation surfaces with the adjoining bones. The path of the lateral line can be followed in certain cheek and skull roof bones. Aquesbi (1988) was able to propose a reconstruction of the skull roof. New specimens, not previously figured by Aquesbi, and a more thorough survey of articulation surfaces and bone contacts, now enable to provide a more detailed, and revised reconstruction of the dermal skull anatomy and to properly compare this new taxon with other onychodonts and early osteichthyans.

All fossil remains are housed at the Muséum national d'Histoire naturelle (MNHN) in Paris, France.

\section{Methods}

In her original publication, Aquesbi (1988) prepared the material by attacking the limestone sediment with formic acid (diluted about 10\%) with addition of tricalcium phosphate. The fossils were easily extracted from the matrix and showed a very good quality of preservation. The specimens that were considered more fragile and certain large jawbones were prepared by transfer in resin. This technique enabled to study aspects of the morphology and ornamentation of the bones on their unexposed surface that was hidden by the matrix; completing previous descriptions by Lehman (1976). In order to thoroughly restudy this material, further bony remains that were not figured by Aquesbi (1988) have been prepared and the resin encapsulating several emblematic specimens has been removed by dilution in acetone for several days. 
X-rays pictures were taken with a Faxitron X-ray cabinet $(43805 \mathrm{~N} ; 110 \mathrm{kV})$. Thin sections were examined under natural transmitted and polarized light with a Zeiss Axiovert 35 microscope. SEM pictures were obtained with a JSM-6000 Plus Jeol Neoscope benchtop SEM (5kV). Illustrations were made on Adobe Illustrator and figures finished in Adobe Photoshop.

\section{SYSTEMATIC PALAEONTOLOGY}

Osteichthyes Huxley, 1880

Sarcopterygii Romer, 1955

Onychodontida Andrews, 1973

Selenodus gen. nov.

(Figs $2-15)$

Type species. Selenodus aquesbiae sp. nov.

Diagnosis. As for type species.

Derivation of name. Greek, selene, moon (referencing the crescent-moon-shaped tubercules present in the scales and dermal bones), and odus (tooth).

\section{Selenodus aquesbiae sp. nov.}

Onychodonte Lehman, 1976, p. 1-34, pl.2 A-D.

Onychodontiforme Aquesbi, 1988, p. 181-196, 2, 4-6, 8.

Onychodont Cloutier and Ahlberg, 1996, p. 456.

Onychodonte Janvier and Zhu, 1994, p. 953.

Derivation of name. After Najat Aquesbi as recognition of her work on the fossil vertebrates from Morocco.

Holotype. MCD 143, left snout and cheek (Aquesbi, 1988; Fig. 2B); Fig. 3.

Referred specimens. MCD 105 (right maxilla), MCD 130a (left supratemporal), MCD 131 (left tabular and lateral extrascapular), MCD 132 (right posttemporal), MCD 133 (right spiracular), MCD 137 (scales, histological cross sections), MCD 138 (left maxilla), MCD 139 (right maxilla), MCD 140 (right ceratobranchial), MCD 141 (left ceratobranchial), MCD 143 (left side of the snout and cheek), MCD 212 (dental platelets and gill rackers), MCD 213 (scales), MCD 215 (isolated teeth), MCD 216 (sclerotic ossicles), MCD 218 (left opercular), MCD 219 (left preopercular), MCD 221 (left parietal), MCD 223 (left prearticular), MCD 224 (right dentary), MCD 226 (left postparietal). 
Diagnosis. Relatively large fish (around 1 meter of estimated length based on the skull dimensions). Maxilla with a rounded posterior outline and a posterior section having a straight ventral margin bearing numerous teeth decreasing in size posteriorly, not reaching its posterior-most tip. Single row of large maxillary and dentary teeth, posteriorly oriented and recurved inwards. Hollow teeth with a thin layer of enamel and dentine, slightly folded at their base. Striated enamel present on the teeth with weakly developed or absent herringbone pattern. Lateral rostral contacting the orbit through a narrow postero-dorsal projection. Presence of a single supraorbital. Numerous pores in dermal bones of the snout, cheek and skull roof. Dermal bones and rounded scales ornamented by small pointy dentine tubercules capped with enamel.

Occurrence. Akka valley, Tindouf bassin, Southern Morocco. Megsem Mdarsal Group, Ahrerouch Formation, late Eifelian, Middle Devonian.

\section{DESCRIPTION}

\section{Snout}

The left side of the snout is represented by the nasal series, lateral rostral, anterior and posterior tectal, supraorbital and lacrimal (Fig. 3). Other distinctive bones of the snout of onychodonts such as the premaxilla, rostral series (median, posterior and median postrostral), and interparietal have not been found. All the dermal bones are ornamented with very small rounded tubercules and some of them display small pores, either associated with the course of the lateral line or related to a sensory function.

The nasal series is represented by two small polygonal bones, forming an arch, and situated antero-dorsally to the orbit (Na, Fig. 3C,D). The most anterior nasal is the smallest of the two, has a pentagonal contour, and it contacts the anterior tectal ventrally and the posterior tectal posteriorly, whereas the most posterior one is bigger, has a rectangular shape and contacts the posterior tectal ventrally and the supraorbital posteriorly. A third but unpreserved nasal was certainly present in-between the two. Both nasals house the supraorbital lateral line canal, as evidenced by perforations visible through the antero-dorsal margins of both bones and large pores on the inner side of the posterior nasal.

The lateral rostral is the largest preserved bone of the snout although it is broken in two (L.Ro, Fig. 3C,D). The anterior portion was labelled "lacrimal" by Aquesbi (1988, figs. 6, 7) and a posterior fragment was not previously assigned to the lateral rostral, neither figured. 
The ornamentation pattern, relative size of the fragments and close observation of the breaking surface now allows to almost fully reconstruct the bone. The general shape of the lateral rostral consists of a subrectangular main body and a well-developed posterodorsal process. The lateral rostral contacts the anterior tectal antero-dorsally, the posterior tectal dorsally and the lacrimal posteriorly. The posterodorsal projection reaches the orbit but contributes little to the orbit rim. The anterodorsal margin shows a clear notch to accommodate the ventral edge of the anterior nostril (a.no, Fig. 3C,D), whereas a slight depression in the posterior margin would have framed the anterior edge of the posterior nostril (p.no, Fig. 3C,D). Both nostrils are oval in shape. The ventral margin of the bone housed the infraorbital lateral line canal (ioc, Fig. 3D) through a well-marked groove that posteriorly prolongs itself into the lacrimal. The long ventral overlapping surface for the dorsal margin of the premaxilla is not preserved. Large pores follow the course of the lateral line ventrally but a different pore cluster, probably of sensory nature, is also developed dorsally, close to the narial opening. In internal view, the lateral rostral displays an antero-posterior depression in the shape of a concave arc connecting both nostrils that certainly housed a nasal tube. The ventral edge of the anterior nostril presents a small but well marked groove forming the anterior-most section of the nasal tube, reminiscent but certainly not homologous to the processus dermintemedius of 'osteolepiforms' (Jarvik 1966).

The anterior tectal is a small, bean-shaped bone that nicely articulates with the anterodorsal margin of the lateral rostral (A.Te, Fig. 3C,D). It frames the dorsal edge of the anterior nostril by a small ridge and contacts the first nasal dorsally and the posterior tectal posteriorly, which excludes the anterior tectal from the orbit rim. The presence of pores indicates that branches of the supraorbital lateral line canal might have pierced the bone.

The posterior tectal is an elongate bone with an hourglass shape, broken in four pieces, but confidently reconstructed based on dermal ornamentation and cleavage pattern (P.Te, Fig. $3 \mathrm{C}, \mathrm{D})$. It was incompletely figured and labelled as belonging to the "supraorbitary series" by Aquesbi (1988). The posterior tectal separates the naris from the anterior margin of the orbit and it is the bone that contributes the most to the orbit rim. It contacts the anterior tectal anteriorly, the nasal series antero-dorsally, the supraorbital posteriorly through a small surface, and the lateral rostral ventrally; the posterior projection of the lateral rostral excludes the posterior tectal from contacting the lacrimal. A large and well-developed flange (visible in inner view, Fig. 3D) allows the lateral rostral to overlap the ventral margin of the posterior 
tectal. A series of pores pierce the bone ventrally and probably belong to the same sensitive pore cluster from the anterior tectal and the lateral rostral.

The supraorbital is a robust bone, situated dorsal to the orbit (So, Fig. 3C,D). It has a rectangular general shape and a concave ventral margin for the dorsal framing of the orbit. It contacts the most posterior nasal bone and a small portion of the posterior tectal anteriorly, and the postorbital posteriorly. The supraorbital is pierced by the supraorbital lateral line canal (soc, Fig. 3D) by a large transversal shaft through the dorsal portion of the bone (the posterior exit of the canal is visible in internal view). Large pores associated with the lateral line canal open in the inner side of the bone.

The lacrimal is the most badly preserved bone of the snout (La, Fig. 3C,D). Only three fragments have been retrieved thus neither the precise contour of the bone nor its dimensions can be confidently assessed. The lacrimal forms the ventral margin of the orbit with the small dorsal fragment displaying a minute concave flange dorsally, matching the curvature of the orbit. The lacrimal contacts the lateral rostral anteriorly and the jugal posteriorly. The precise location of the lacrimal relative to both the incompletely preserved maxilla and unknown premaxilla cannot be stated. The infraorbital lateral line canal (ioc, Fig. 3D) passes from the anterior tectal into the lacrimal through a narrow and well-defined antero-ventral groove and turns dorsally behind the posterior nostril. Pores are clearly seen (po, Fig. 3D) indicating the course of the infraorbital canal.

Several small and extremely fragile sclerotic ossicles have been retrieved (sc.o, Fig. $3 \mathrm{C}, \mathrm{D})$. Sclerotic plates are square to slightly rectangular in shape, with a broader distal end and unornamented; the anterior corners are rounded, the external surface is slightly convex whereas the internal surface is gently concave. Their exact number cannot be determined, although given their size and the approximate size of the orbit there must have been around 30 ossicles per orbit.

\section{Cheek}

The left cheek of Selenodus is represented by the postorbital, jugal, maxilla, a putative spiracular, and fragments of the squamosal and preopercular (Figs. 3-7) (described below in the opercular series). As for the snout, the dermal cheek-bones are ornamented with tubercules and pores.

The jugal is a robust, pear-shaped bone, forming the posterior margin of the orbit rim (Ju, Fig. 3C,D). It contacts the postorbital dorsally and the lacrimal ventrally, however its 
ventral margin is unclear. Posteriorly, the jugal contacts the squamosal, but as for the lacrimal, the articulation between the jugal and the squamosal fragment is not confident. The jugal carries the junction of the infraorbital and postorbital lateral line canals. X-rays clearly illustrate the course of the three main lateral line branches (Fig. 18A) but due to the bone thickness putative smaller secondary branches are not visible. The X-rays also confirm that a ventral branch of the lateral line from the jugal into the maxilla is lacking. Pores associated with the lateral lines are visible in outer and inner view.

The squamosal is the largest bone of the cheek but it is incompletely preserved as a roughly triangular fragment (Sq, Fig. 3C,D). Two small depressions on the antero-dorsal and antero-ventral corners of the bone might be associated with overlapping surfaces of the postorbital and jugal respectively. A long and narrow flange is well-developed in the straight dorsal margin of the bone suggesting a putative overlapping surface for a putative spiracular (?ov.Sp, Fig. 3D). Anteriorly, a concave depression suggests the occurrence of a spiracular opening, probably situated at the dorsal junction with the postorbital. The path of the lateral line canal running through the jugal is clearly visible in the antero-ventral corner of the bone (jc, Fig. 3C,D), preserved as a large and hollow shaft. Several pores are discernable in outer view but a distinctive pit line is either absent or not preserved.

The postorbital is a large and relatively thick bone forming the postero-dorsal margin of the orbit, decreasing in thickness from the orbital rim to its posterior edge (Po, Fig. 3C,D). It contacts the supraorbital anteriorly, the jugal ventrally and possibly the antero-dorsal corner of the squamosal. The dorsal margin is slightly eroded but displays an overlapping surface for a skull roof bone, either the parietal or a putative intertemporal. The course of the postorbital lateral line canal (poc, Fig. 3D) is evidenced by the presence of a shallow ventral groove running parallel to the orbital rim. The supraorbital lateral line canal prolongs itself from the supraorbital into the postorbital through a small hole in the antero-dorsal corner and turns ventrally posterior to the orbit and exits into the jugal ventrally (poc, Fig. 3D). However, it is not clear whether the supraorbital canal branches off from the postorbital canal immediately posterior to the supraorbital and dorsal to the postorbital bone in soft tissue (as proposed in Onychodus), or through an unpreserved putative intertemporal bone. A series of pores of different sizes are associated with the course of the lateral line canal in the postero-dorsal portion of the bone.

The maxilla is the largest of all preserved bones. It is represented by three fragments (Figs. 4-6), two of them articulating and belonging to the right side of the skull (Figs. 4-5) and 
a smaller one probably from the left side (previously considered a dentary by Lehman, 1976) (Fig. 6). The largest maxillary fragment (Fig. 3) is roughly rectangular in shape. The posterior portion is straight, lacks a distinctive ventral curbature, displays parallel dorsal and ventral margins, and has a rounded expansion at the rear (p.exp, Fig. 4D). The dorsal and ventral margins of the large fragment display an arc-shaped depression resulting in a faint ridge longitudinally crossing the bone. The anterior portion of the maxilla (Fig. 5) is represented by a large fragment, rectangular in shape but incompletely preserved, lacking the dorsal edge. This fragment shows an inward curvature of the ventral margin, close to the breaking point with the larger fragment. The anterior portion of the maxilla certainly extended forward into the snout but the junction with the unpreserved premaxilla cannot be confidently reconstructed. The remaining fragment (Fig. 6) probably belongs to the left maxilla and consists of a roughly squared fragment, probably located at the anterior most portion of the maxilla. The posterior margin is broken but the anterior margin displays an articulation facet for the premaxilla (art.Pmx, Fig. 5E,6F).

Internally, the maxilla displays a strongly developed horizontal ridge (int.ri, Fig. 4D, $5 \mathrm{~F}$ ), which increases in height from the posterior most portion of the bone and then runs parallel to its ventral margin. This horizontal ridge might have connected the maxilla with the ectopterygoid and dermopalatines bones. The teeth are ventrally inserted into this ridge, forming a continuous row, roughly uniform in width and size, and with the largest teeth situated anteriorly and gradually reducing posteriorly. Overall, 11 teeth are preserved in the anterior fragment of the right maxilla (Fig. 5) and 6 teeth in the smaller fragment of the right maxilla (Fig. 6); the largest fragment from the left maxilla preserves the bases of 14 teeth (Fig. 4). The teeth are recurved inwards and slightly backwards; the base of the largest teeth is gently folded (t.fo, figs. 5E,F). Numerous ovate replacement sockets (r.s, figs. 4E, 5E) occur between the preserved teeth with no apparent strictly alternate pattern. The main teeth row is flanked by small denticles (de, Fig. 5D,E) on the labial side, laterally grading into the more rounded tubercules of the dermal ornamentation. The inner pulp cavity of the teeth is large and hollow (p.ca, Fig. 4E-5E). The small labial denticles also display a pulp cavity. The maxilla is ornamented by small tubercules (tu, Fig. 5D, 6D). A series of pores of sensory nature pierce the dermal ornamentation (po, Fig. 4D, 5D, 6D), some of them are fairly large. However, their relationship with the infraorbital lateral line is not clear.

A putative right spiracular is entirely preserved. It is a small and elongate, comashaped bone, with an enlarged posterior margin and a tapering dorsal portion (Fig. 7E-H). It is 
heavily ornamented by large rounded tubercules in the outer surface, the inner surface being smooth and displaying several radial marks suggesting a possible surface of muscular attachment. The posterior portion carries two reduced overlapping surfaces, dorsally for the tabular or the lateral extrascapular (?ov.Ta/L.Ex, Fig. 7G,) and ventrally for the opercular (? ov.Op, Fig. 7G). The strongly curved and concave ventral margin might also correspond to an overlapping surface; however, it is not straight and does not match the elongate overlapping surface of the left squamosal (?ov.Sp, Fig. 3D). This bone can thus also be an extratemporal but since it was not found articulated, the reconstruction of the upper portion of the cheek of Selenodus remains uncertain.

\section{Opercular series}

The left opercular series is poorly preserved and comprises the opercular and preopercular (Fig. 7). Both bones are greatly altered due to erosion and chemical preparation that have removed most of the outer and inner osseous lining. The overlapping surfaces have nevertheless been preserved and allow a confident reconstruction of their relative arrangement. No subopercular bone has been found.

The opercular is an extremely thin bone, becoming thinner towards its incompletely preserved median region (Op, Fig. 7C,D). It has a pentagonal contour, with a pointed posterodorsal corner. The posterior and ventral margins are entirely preserved and meet in a square angle at the postero-ventral corner whereas the antero-dorsal edge might have been more rounded or probably tapering. The opercular overlaps the lateral extrascapular dorsally (ov.L.Ex, Fig. 7D), the preopercular ventrally, and might have posteriorly overlapped the dorsal portion of an unpreserved cleithrum through an overlapping surface extending across the dorsal, ventral and posterior margins of the bone (ov.Cl, Fig. 7D). The weathering has removed the osseous surface of the bone, but some 'bumps' visible close to the anterior margin might indicate the occurrence of ornamenting tubercules.

The preopercular is badly preserved and displays the same weathering pattern as the opercular (Pop, Fig. 7C,D). The preopercular is the posterior most bone of the cheek and carries the preopercular canal as a continuation of the jugal lateral line canal, parallel to the dorsal margin of the maxilla, to the rear of the cheek. The preopercular has a roughly rectangular shape and preserves the dorsal, anterior and ventral edges relatively well, however the posterior portion is broken. The preopercular is overlapped dorsally by the opercular, anteriorly by the squamosal, and ventrally by the maxilla. The overlapping surface for the 
opercular straddles across the entire dorsal margin. Ventrally, an overlapping surface for the maxilla is partially preserved (ov.Ma, Fig. 7C). A small fragment of a putative overlapping surface for the squamosal is also preserved anteriorly (ov.Sq, Fig. 7C), suggesting that the extension of the anterior projection of the opercular and preopercular across the cheek might have been similar. As for the opercular, the intensive weathering has removed the bony surface, exposing the course of the preopercular canal of the lateral line (popc, Fig. 7C), which runs across the bone, close to the dorsal margin.

\section{Skull roof}

A small fragment of a putative parietal solely represents the ethmoid division (Fig. 8A-D). The otoccipital portion of the left side of the skull roof is more complete and is represented by three roughly complete bones: the supratemporal, tabular and lateral extrascapular (Fig. 8E$\mathrm{H}$ ) and a small fragment of a putative postparietal (Fig. 8I-L). A putative postemporal is also described here (Fig. 8M-P). The margins of all bones are slightly eroded and thus their exact contour cannot be determined with precision. The postotic lateral line (poc, Fig. 8G,H) runs in a slightly sinusoidal manner through the supratemporal, tabular and lateral extrascapular and no branching of the lateral line indicates a deviation of this canal from these three bones.

A putative left parietal is well preserved (Fig. 8A-D). It was recovered from the same sediment block as a canal bearing bone fragment, both elements were closely located, although not in contact. The canal bearing bone, probably the third element from the nasal series, carries a deep shaft for the supraorbital lateral line canal but is extremely badly preserved (not figured). No lateral line canal pierces the parietal and no pit-line is evident. The bone is ornamented with small tubercules (tu, Fig. 8B), similar to those present in other skull roof bones. A small overlapping surface might have accommodated some of the nasal elements (?ov.Na, Fig. 8B). The inner side is featureless.

The supratemporal is incompletely preserved and has been partially reconstructed based on the erosive and ornamentation pattern of the bone surface and the course of the lateral line in the inner side (St, Fig. 8F,G). The supratemporal is wider that the tabular (which it contacts posteriorly), slightly arched laterally, and carries the anterior portion of the postotic lateral line canal (potc, Fig. 8H). It is ornamented by small rounded tubercules and displays an array of pores posteriorly, following the course of the lateral line.

The tabular is an elongate and narrow bone, contacting the supratemporal anteriorly and the lateral extrascapular posteriorly (Ta, Fig. 8F,H). It has a stretched S shape, with 
roughly parallel margins and relatively small articulation surfaces for the supratemporal and lateral extrascapular. The medial margin display a faint overlapping surface for the postparietal (ov.Pp, Fig. 8H). The postotic sensory line runs antero-posteriorly through the middle section of the bone (potc, Fig. $8 \mathrm{H}$ ), parallel to its margins. A tabular transverse pit-line is inconspicuous due to erosive abrasion or absent. As the supratemporal, the tabular is ornamented by small tubercules and pores associated with the lateral line and restricted to the postero-lateral portion of the bone.

The lateral extrascapular is the largest of the skull roof suite of preserved bones (L.Ex, Fig. 8F,H). It has a triangular general outline, with a reduced anterior end for the articulation with the tabular and a broad posterior portion. The median commissure develops posteromedially forming an arched medial margin (m.co, Fig. 8F). The overlapping surface for the postparietal is badly preserved. In internal view, several centrifugal growth lines are visible developing from the ossification centre of the bone, located at the branching point of the supratemporal commissural canal (stcc, Fig. 8H) from the main lateral line canal. The course of the lateral line does not follow the lateral contour of the bone but rather forms an inward arch. The ornamentation of small tubercles is more extensively preserved than in the tabular and supratemporal and several pores occur on the surface, close to the median and posterior margins of the median commissure, associated with the path of the lateral line.

A small fragment of a flat bone can be tentatively assigned to a postparietal (Fig. 8IL). It is extremely thin and, as the other bones of the skull roof, completely ornamented with small crescent-moon tubercules (tu, Fig. 8K). The inner side is transversally broken and featureless.

A putative right posttemporal is entirely preserved (Fig. 8M-P). This bone was labelled "opercular" by Lehman (1976) and Aquesbi (1988) but bears a great similarity with Onychodus supratemporal (Andrews et al. 2006) and with Bukkanodus tabular (Johanson et al. 2007), which also carry a lateral line canal. It has a roughly drop shape, with a rounded and large medial portion and a narrower and angled posterior edge. It carries the lateral line, posterior to the lateral extrascapular, as evidenced by the antero-lateral and postero-lateral openings and the thickened arc near the medial margin. Pores associated with the course of the lateral line occur both dorsally and ventrally (po, Fig. 80). Two overlapping surfaces can be recognised: a postero-lateral narrow depression, possibly for the supracleithrum (?ov.Scl, Fig. 8O), and an elongate overlapping surface straddling the anterior margin for the lateral extrascapular (ov.L.Ex, Fig. 8O). These alleged overlapping surfaces were incorrectly 
associated with the squamosal and the subopercular, respectively (Aquesbi 1988). The bone is slightly concave ventrally and bears a prominent ridge across its medial margin.

\section{Branchial arches}

The only endoskeletal elements known in Selenodus are two large bones from the branchial arches (Fig. 9). Both are long and narrow, rodlike bones with a roughly propeller shape and equal in size, probably corresponding to the ceratobranchial series. Given their slightly arched shape mesially oriented MCD 140 might belong to the right side whereas MCD 141 might be from the left side. Their exact position in the branchial series is not possible to determine, but due to their elongate shape and lack of distinctive features an anterior or central position along the series might be plausible.

Both ceratobranchials are hollow, indicating that the internal endochondral ossification was weakly developed and was maintained in a cartilaginous state. The moderately thick periosteal bone is pierced by numerous pores and grooves (po, Fig. 9J, N). Articulation surfaces at the extremities of the bone are lacking, probably due to the extreme thinness of the perichondral lining and the occurrence of cartilaginous pads for the articulation with the epibranchials and basibranchials. Both bones are hemicylindrical in cross section and display a clearly marked shallow groove on the ventral surface for the efferent artery and branchial nerve (Cb.gr, Fig. 9L,P). The groove is less defined and fades distally but it becomes narrow and deeper proximally, at the level of the putative articulation with the epibranchials. The bones are arched in cross section and expanded at their proximal end, which is broader that the medial shaft.

Numerous isolated denticulated plates (tooth plates or gillrakers) have been recovered (Fig. 12B). Several of these denticulated plates have been found isolated after dilution of the calcareous nodules; however none have been found fused to the branchial bones. Dental plates ornamented by a cluster of denticles can also be found over the palate bones, located on the pharynx or gill arches (pharyngeal bones) (Fig. 12C). The number of small denticles ornamenting the plates is variable as well as their orientation.

\section{Mandible}

The mandible is incompletely preserved. It is solely represented by the posterior portion of a right dentary and by a large fragment of a left prearticular (Figs. 10-11). Putative infradentaries, gulars and branchiostegal bones as proposed by Aquesbi (1988) cannot be 
confidently identified due to their fragmentary state of preservation. Parasymphysial tooth whorls and sigmoid tusks, as well as coronoid bones, are missing.

The dentary is incompletely preserved and is represented by two fragments (Fig. 10). The large fragment comprises the most posterior portion of the dentary whereas the smaller fragment is more anteriorly situated; however despite the identical state of preservation and relative size, the pieces do not fit together and thus the precise location of the small fragment along the dentary cannot be certainly stated. The symphysial region is entirely missing. The large dentary fragment is narrow and generally straight. The posterior edge tapers and the rear was probably overlapped by the maxilla. The ventral surface is inwardly curved. The lingual side is badly preserved but a moderately developed and narrow mesial ridge (int.ri, Fig. 10F) can be perceived, running longitudinally but not reaching the most anterior portion. This dentary internal ridge is thought to support the unpreserved coronoid series. Together, the two dentary fragments carry 19 teeth sockets and 8 of them retain the teeth, either partially missing the distal tip or broken at their base. The teeth are relatively larger that those of the posterior region of the maxilla and are recurved inwards. Replacement sockets (r.s, Fig. 10E) are ovate in dorsal view and occur between the teeth with an uneven alternate pattern, as in the maxilla. The main row of large teeth is labially flanked by a smaller row of minute denticles (de, Fig. 10E), which, as in the maxilla, grade into the rounded tubercules of the labial side. The pulp cavities (p.ca, Fig. 10E) are apparent in the teeth, as well as in some of the denticles. In the teeth, the pulp cavity is large and hollow at the midsection but some teeth broken at their most lower portion display dentine plications (pli, Fig. 10E) around the pulp cavity. The dentary is ornamented by numerous rounded tubercules (tu, Fig. 10D). No distinctive pores associated with a putative sensory canal are visible.

The prearticular is among the largest bones preserved, although the anterior most portion (and probably tapering expansion) is missing (Fig. 11). The bone is thin and shiny on the labial (non-buccal) surface, whereas it is ornamented on the lingual (buccal) side. The lingual surface is gently convex and bears a large field of small tubercules or denticles (tu, Fig. 11D), densely concentrated on the postero-ventral corner and straddling the ventral margin but decreasing in size anteriorly, probably due to erosive processes. Some broken tubercles are hollow and show a small pulp cavity. However, these denticles are rounded and different from the pointy denticles lining the main row of teeth from the dentary and maxilla. The posterior corner of the bone displays a large V-shaped gap for the articulation with the unpreserved articular (Art.g, Fig. 11D). Dorsally, the broken posterior part of the cleavage 
shows the cartilage attachment of the two bones. The prearticular shows an unornamented thickened dorsal crest (d.cr, Fig. 11D,E), more developed posteriorly into two concave furrows and tapering anteriorly, probably for the support of the posterior coronoid bones. The lateral (non buccal) surface is concave and displays a well-developed dorsal flange or extension (d.fl, Fig. 11E), corresponding to the ventral surface of the dorsal crest. A dorsal process as described in Onychodus (Andrews et al., 2006) is absent but an internal projection is well developed (int.pr, Fig. 11F). The attachment of the adductor muscles (a.s.add.mu, Fig. $11 \mathrm{~F})$ might have occurred directly onto this internal expansion, as well as in the ventral lamina. Given the relative size of the dentary and the prearticular, the lower jaw of Selenodus might have been deeper than what the narrow but incompletely preserved dentary suggested.

\section{Scales}

Scales are abundantly preserved in articulation and were previously figured by Lehman (1976) and Aquesbi (1988). They correspond to the scales located immediately behind the skull but some isolated scales might come from more posterior regions of the trunk. No apparent morphological variability occurs depending on their location of the body. The scales are rounded in shape (Fig. 12A). The external surface is composed of two well-defined exposed and overlapped areas, differing in ornamentation. The exposed portion is uniformly covered in small characteristic pointy or crescent-moon-shaped tubercules (Fig. 12A1,2), well developed near the edge of the exposed and overlapped areas and decreasing in size posteriorly. The denticle apex points posteriorly with an anterior depression. The large overlapped area is not ornamented but displays concentric growth lines crossed by fine radial ridges (Fig. 12A1,3). The internal surface is smooth and gently concave with concentric growth lines spreading from the centre of the scale.

\section{Histology}

Teeth. As previously described, several large broken teeth from the maxilla and dentary display dentine folds around a hollow pulp cavity, but solely at their base (pli, Fig. 10B2). This condition represents a simple form of plicidentine (i.e., simplexodont plicidentine sensu Meunier et al., 2015a,b), similar to the one described and figured for Onychodus (Schultze, 1969). These orthodentine plications are certainly related to the enamel folds present at the base of certain maxillary teeth (t.fo, Fig. 4B2,C2). The rest of the pulp cavity is not filled by osteodentine and thus appears as hollow, with a relative thin outer lining of dentine and 
enamel at the lower and middle portions of the teeth but increasing in relative thickness towards the tip (Fig. 10B2).

Externally, SEM data illustrate the occurrence of enamel striae along the entire length of several isolated teeth retrieved after dissolution of the rocky matrix (Fig. 13). However, these teeth do not belong to the large parasymphysial tusks and thus the enamel striae are not as marked as in Onychodus (Smith, 1979, 1989; Andrews et al., 2006) or Strunius (Gross, 1956). A weakly developed herringbone pattern along the enamel striae can be hardly visible in certain regions of the teeth (Fig. 13A) probably due to an important erosive and chemical abrasion during preparation. The radial arrangement of enamel crystals is also not clearly visible due to preservation conditions (Fig. 13B).

Scales and dermal bones. The microstructural organisation of the squamation has been evaluated through "classical" histological cross sections given the good overall preservation of the material (Fig. 14, 15). The scales of Selenodus are composed of two well-defined layers: an external layer (subdivided into a thin enamel layer (e), an underlying layer of dentine (d), a middle layer of woven-fibered bone (vb) with numerous vascular canals), and a basal layer of parallel-fibered bone (lb).

In the scales, the enamel and dentine layers form the tubercules ornamenting the exposed area (i.e., odontodes as made from odontogenic components). The enamel (e) is a single-layered sheet of approximately $50 \mu \mathrm{m}$ in thickness (Fig. 14A1-3, 15A1-2). The odontodes have a pointy or concave lenticular outline in cross section with the enamel layer being uniformly developed throughout the exposed area of the odontode. No cytoplasmic prolongations are seen in the enamel, thus ruling out the occurrence of enameloid. The dentine layer (d) is more variable in thickness (between 150-200 $\mu \mathrm{m}$ ) and forms the base of the odontodes, laying a top the middle bony layer underneath (Fig. 14A1-2, 15A1-2).

Recrystallization has mostly affected the dentine and thus dentinal tubes and pulp cavities are hardly discernable. However, the most striking feature is the occurrence of at least two generations of superimposed odontodes, with little or no resorption of the older generation (Fig. 14A1-3). Vascular canals (vc) connected horizontally surround the buried odontodes or are either located beneath the dentine within a relatively thin and irregularly developed layer made of woven-fibered bone (less than $100 \mu \mathrm{m}$ ) (Fig. 14A1,2, 15A1-2). This middle vascular bone (vb) layer (i.e., spongiosa) varies in thickness across the scales but seems more homogenously developed in the dermal bones. The woven-fibered bone of the spongiosa forms the radial striae of the overlapped area of the scales (Fig. 15A2). The basal layer is 
made of parallel-fibered, lamellar bone (lb) with a variable orientation of the collagen plies (Fig. 14A4, B1-2). This plywood-like arrangement of the bony lamella is characteristic of the isopedine layer of the scales of numerous sarcopterygians (e.g., Mondéjar-Fernández, 2018). In some sections of the isopedine, the irregular contact of the collagen plies evidences the occurrence of Mandl's corpuscules, attesting of successive mineralization events across the basal layer. Several small osteocyte lacunae and canaliculi are visible. The ossified isopedine layer accounts for approximately half of the scale total thickness (approximately $250 \mu \mathrm{m}$ ). No distinctive bony keel or boss is found underneath the basal layer.

The dermal bones display a similar microstructure (Fig. 15B); the only difference with the scales being the lesser number and larger size of the odontodes, the more uniformly developed spongiosa with numerous and relatively larger vascular canals, and the relatively thinner basal layer (Fig. 15B1). No distinctive system of pores and canals pervade the dentine and enamel layers, and the vascular canals of the spongiosa do not open to the surface; the occurrence of cosmine can thus be ruled out.

\section{DISCUSSION}

The unpublished material and redescription of Selenodus adds to our knowledge on the morphological diversity of onychodonts and sheds light on patterns of character distribution in early osteichthyans. Onychodonts stand out among early osteichthyans by a distinctive and seemingly specialised set of features, however several of these traits have been resolved as being, in part, primitive for sarcopterygians and even osteichthyans based on recent phylogenetic analysis (e.g., Lu et al. 2016a). Andrews et al. (2006) listed a detailed compendium of synapomorphies of onychodonts that can now be updated by new information from Bukkanodus, Qingmenodus and Selenodus (for a discussion on onychodont synapomorphies see Andrews et al. 2006; Johanson et al. 2007; Lu \& Zhu 2010; Lu et al. 2016a). Of these synapomorphies, only the features preserved in Selenodus will be evaluated and discussed.

\section{The snout and cheek}

Supraorbital bones are variably developed in osteichthyans, however the presence of at least two supraorbitals is considered a crown sarcopterygian synapomorphy. In onychodonts, two supraorbitals are present in Strunius (Jessen 1966) and Onychodus (Andrews et al. 2006), 
whereas they are unknown in Grossius (Schultze 1973) and Qingmenodus (Lu \& Zhu 2010; Lu et al.2016a) (Fig. 16). Actinistians are known to present numerous supraorbitals; four in Miguashaia (Cloutier 1996) and possibly Serenichthys (Gess \& Coates 2016), six in Diplocercides (Stensiö 1937), and variably in younger coelacanths but never less than four (Forey 1998) (Fig. 17C,D). Selenodus is thus remarkable among sarcopterygians in possessing a single supraorbital, reminiscent of the condition of Guiyu (Qiao et al.2010) and Cheirolepis (Pearson \& Westoll 1979; Arratia \& Cloutier 1996) (Fig. 17A,B). However, as opposed to psarolepids and actinopterygians, the supraorbitals of sarcopterygians are more dorsally situated and more distant from the nostrils. Moreover, in onychodonts the supraorbital lateral line canal pierces the dorsal portion of the supraorbitals, as in early actinistians like Miguashaia (Cloutier 1996; Forey 1998) and Gavinia (Long 1999), but opposed to being solely carried by the nasal series into the parietals as in dipnomorphs (e.g., Holoptychius) (Jarvik 1972) and tetrapodomorphs (e.g., Gogonasus) (Long et al. 1997).

The nasal series of onychodonts carries the anterior portion of the supraorbital lateral line canal, do not contact the anterior nostril, and exclude the anterior tectal from contacting the premaxilla. In Selenodus, the nasal series was probably composed of four nasal bones, nasals 1 and 3 being unknown (the gap between the antero-dorsal corner of the lateral rostral and the first preserved nasal might have accommodated the first nasal of the series, contacting the anterior tectal whereas the space between the second and fourth nasal was certainly occupied by a similarly sized bone) (Fig. 2, 16C). In other onychodonts, nasal bones are only known in Onychodus where there are three (Andrews et al.2006), whereas in Grossius (Schultze 1973) and Strunius (Jessen 1966) the snout is too badly preserved to allow a precise reconstruction. In Qingmenodus (Lu et al. 2016a) the putative enamel covering of the ethmosphenoid blurs the bone sutures, except between the premaxilla and the median rostral, a condition similar to the cosmine-covered ethmoids of basal dipnomorphs and tetrapodomorphs (e.g., Powichthys, Diabolepis, Tungsenia and Kenichthys) (Jessen 1980, Chang \& Yu 1984, Chang \& Zhu 1993; Lu et al. 2012). The occurrence of two nasal bones is common in early osteichthyans and certainly represents the primitive condition as found in Guiyu (Zhu et al. 2009; Qiao \& Zhu 2010). The early actinopterygian Cheirolepis also possesses two nasals (Pearson \& Westoll 1979; Arratia \& Cloutier 1996; Mickle 2015) as opposed to a single nasal of more derived "palaeonisciforms" (e.g., Mimipiscis and Moythomasia) (Gardiner 1984). Among sarcopterygians, the nasal series comprises numerous bones but difficult to number with precision (Ahlberg 1991). 
The shape and connections of the lateral rostral are among the synapomorphies of Onychodontida (see Andrews et al. 2006; Johanson et al. 2007). In Strunius (Jessen 1966), Qingmenodus (Lu \& Zhu 2010; Lu et al. 2016a) and Grossius (Schultze 1973) the lateral rostral is unknown, but in Bukkanodus (Johanson et al. 2007), Onychodus (Andrews et al. 2006) and Selenodus the lateral rostrals are similar in shape and all display a narrow posterodorsal projection contacting the orbit and a main body of the bone framing both nostrils (Fig. 2, 3A, 16). Early actinistians also present a lateral rostral surrounding both anterior and posterior nostrils. In Serenichthys (Gess \& Coates 2016) and Rhabdoderma (Forey 1998) the lateral rostral is excluded from contacting the orbit by the lachrymojugal and the preorbital, whereas in Gavinia (Long 1999) the lateral rostral contacts the antero-ventral corner of the orbit, as in onychodonts (Fig. 16, 17C). The contact of the lateral rostral with the orbit can thus be considered a synapomorphy of onychodonts and early actinistians (Lu \& Zhu 2010). In other sarcopterygians, the lateral rostral never reaches the orbit (Ahlberg 1991). Actinopterygians do not possess a lateral rostral as in sarcopterygians, the bone framing both nostrils and contacting the orbit as in onychodonts is the nasal.

Problematic homologies of the snout bones in osteichthyans are nevertheless common (see Borgen 1983; Schultze 2008; Mickle 2015). The arrangement of bones in the snout and cheek of sarcopterygians has been shown to be greatly variable and the establishment of an overall scheme of homology for the Sarcopterygii has been difficult. Nevertheless, a consensus has started to emerge in recent years (see Ahlberg 1991; Schultze 2008). Within onychodonts, the organisation of the snout and cheek of Grossius remains problematic. In Schultze's (1973) reconstruction, Grossius displays a large, single nostril anterior to the orbit and two bones framing the ventral margin of the orbit (Fig. 16A). The anterior bone, contacting the orbit and the posterior edge of the single naris is labelled "lacrimal" whereas the posteriorly located bone, contacting the orbit and the jugal is labelled "infraorbital bone". Infraorbital ossifications between the lacrimal and jugal are known to occur in Carboniferous and younger actinopterygians (Schultze 2008) but they are unknown in all other onychodonts and their occurrence is rare amongst sarcopterygians (Gai et al.2017) with the exception of dipnoans (e.g., Griphognathus, Chirodipterus) (Miles 1977). The snout of Grossius is damaged and thus it is not possible to ascertain whether the single preserved narial opening is indeed a single naris, the anterior, or the posterior nostril. In the hypothetic case of an anterior nostril (the posterior nostril being inconspicuous due to weathering of the infraorbital region of the snout) or a posterior naris displaced anteriorly to merge with the anterior naris, the 
"lacrimal" would correspond to the lateral rostral and would contact the orbit, as in other onychodonts, and the "infraorbital" would correspond to the lacrimal, contacting the orbit ventrally and the jugal posteriorly. It is currently not possible to unravel the snout arrangement of Grossius without further and in depth study of an otherwise threedimensionally and well preserved specimen. A similar case of a single nostril is known in Strunius in which the small size of the specimens and badly preserved snout also hampers to precisely reconstruct the anterior portion of the skull (Jessen 1966).

Equidimensional preopercular and squamosal is also listed as an onychodont synapomorphy, as displayed in Onychodus and Strunius (Fig. 16B,D). In Selenodus, the preopercular is not entirely preserved but if we consider the general arrangement of the cheek of other sarcopterygians, in which the preopercular contributes to the posterior margin of the cheek and generally ends at the same level of the rear of the maxilla, then the squamosal might have been larger than the preopercular. The condition in Grossius is again remarkable. Schultze (1973) reconstructed the cheek following the porolepiform nomenclature with multiple squamosals. However, it is clear that the first squamosal (labelled "squamosal 1") is a true squamosal whereas the "squamosal 2" corresponds topographically to a preopercular. Thus, in Grossius, the preopercular is much larger than the squamosal and forms the majority of the cheek, as opposed to other onychodonts and known sarcopterygians (Ahlberg 1991). In Selenodus, the squamosal is known from a fragment significantly larger than the preopercular. Relative size variation between the squamosal and the preopercular in onychodonts is thus more variable than previously considered (Fig. 16), matching the variability also know in actinistians (e.g., Gess \& Coates 2016).

As opposed to other sarcopterygians (like actinistians and porolepiforms) where the opercular is always larger than the preopercular and posteriorly situated (Jarvik 1972; Ahlberg 1991; Cloutier \& Schultze 1996; Forey 1998), a reduced opercular region is another diagnostic feature of onychodonts. The opercular and preopercular are roughly equivalent in length in Onychodus (Andrews et al. 2006), whereas in Strunius and Grossius the preopercular is twice as large as the opercular (Jessen 1966; Schultze 1973) (Fig. 16). In Selenodus, the opercular-preopercular complex is relatively narrow as opposed to the more elongate complex of Onychodus. When compared with other osteichthyans, the preopercular of onychodonts appears enlarged and usually occupies a more ventral position relative to the opercular than in actinistians for instance, where a similar position is occupied by the subopercular (Forey 1998; Gess \& Coates 2016). An anterior position of the preopercular 
relative to the opercular represents the primitive state for osteichthyans, as seen in early actinopterygians (e.g., Cheirolepis) (Pearson \& Westoll 1979; Arratia \& Cloutier 1996) and Guiyu (Zhu et al. 2009; Gai et al. 2016) (Fig. 17A,B). However, the condition in onychodonts is derived with respect to this primitive condition. In Onychodus (Andrews et al., 2006), the anteriorly tapering opercular extends to the level of the ventral process of the preopercular. In Selenodus, the opercular extends slightly anterior to the preopercular (Fig. 16C) as in Strunius in which the anterior margin of the opercular tapers anteriorly to the preopercular (Jessen 1966). The case of Grossius (Schultze 1973) with a remarkably large preopercular and anteriorly situated to the opercular is, again, unique within onychodonts and constitutes a secondary return to the primitive condition of osteichthyans.

Spiracular bones are common in osteichthyans, however their homology is still debated. The spiracular bone of onychodonts could be homologous to the dermohyal of early actinopterygians (e.g., Mimipiscis, Moythomasia, Gogosardina) (Gardiner 1984; Choo et al . 2009), whereas the spiracular of actinistians could be homologous to the porolepiform prespiracular (Ahlberg 1991). A spiracular bone is known in Onychodus (Andrews et al. 2006) and Strunius (Jessen 1966) but absent from Grossius (Schultze 1973). The importance of the spiracle can also be evaluated by the occurrence of a notch on the lateral margin of the supratemporal and tabular bones and its size can also be variable. Accordingly, Qingmenodus and Strunius show a large spiracular notch whereas Onychodus displays a smaller one, and no distinctive opening is present in Grossius (Lu et al. 2016a). In Selenodus, a notch on the posterior margin of the postorbital matching a depression on the antero-dorsal corner of the squamosal might hint towards the presence and putative location of a spiracle. However, neither the size of a putative spiracle nor the connections between the spiracular and a putative extratemporal bone can be confirmed in Selenodus due to the poor preservation of the dorsal region of the cheek.

\section{Skull roof}

The elongation of the postparietal portion of the skull roof relative to the parietal portion is considered an evolutionary trend within onychodonts (Janvier 1996; Johanson et al. 2007; Lu $\&$ Zhu 2010) and represents a derived feature among osteichthyans. The elongation of the postparietals is also correlated with the posterior tapering of the bones, displacing the lateral extrascapulars laterally, a condition convergently acquired with rhizodontids among sarcopterygians (Andrews 1985; Long 1989; Johanson \& Ahlberg 1998, 2001). The 
posteriorly broadening, L-shaped postparietals of Qingmenouds (Lu \& Zhu 2010) more closely resemble the condition of Strunius and Bukkanodus (Jessen 1966; Johanson et al. 2007) than the roughly rectangular postparietals of Grossius and Onychodus (Schultze 1973; Andrews et al. 2006) (Fig. 18). The reconstruction of the otoccipital skull roof on Selenodus is tentative, but the general alignment of the supratemporal, tabular and lateral extrascapular suggests a straighter outline of the postparietals and a narrow postparietal shield, more similar to the condition of Grossius and Onychodus and somehow intermediate between the shared condition of Strunius and Qingmenodus.

In all known sarcopterygians, the postparietals are laterally flanked by two lateral linecarrying bones: supratemporal and tabular (with the exception of porolepiforms that have no separate supratemporal and the lateral line canal is carried anteriorly by the postparietals) (Jarvik 1972; Ahlberg 1991). The sinousoid course of the postotic lateral line canal in Selenodus is similar to the condition of Strunius but different from the straighter course of Onychodus and Grossius (Jessen 1966; Schultze 1973; Andrews et al. 2006). In onychodonts, the relative position of the tabular to the posterior margin of the skull is variable. Bukkanodus and Strunius display a typical sarcopterygian condition, in which the tabular is close to, or aligned with, the posterior margin of the postparietal, placing the lateral extrascapular along the posterior margin of the skull (Jessen 1966; Johanson et al. 2007). In Onychodus and Grossius, the tabular is more anterior, as is the lateral extrascapular, with both bones contacting the lateral margins of the postparietal (Schultze 1973; Andrews et al. 2006). The homology and relative disposition of the supratemporal, tabular and lateral extrascapulars is now well established in sarcopterygians (e.g., Ahlberg 1991). However, the published skull roof reconstruction of Grossius remains problematic since it followed the now disused terminology of Jarvik $(1944,1967)$. Now it is possible to correctly state that the "intertemporal" of Grossius should accordingly be labelled supratemporal, the "supratemporal" would be the tabular and the "tabular" would be the lateral extrascapular (the latter correctly figured and labelled as contacting the median extrascapular and the opercular in the transversal reconstruction in Fig. 7B but erroneously labelled in Fig. 7A) (Schultze 1973) (Fig. 18). According to this new nomenclature, the supratemporal is remarquably large and would contact the orbit, a unique condition among osteichthyans. The tabular of sarcopterygians usually carries a pit line (e.g., Jarvik 1980; Ahlberg 1991). In onychodonts, it has been identified in Bukkanodus, Strunius and Onychodus (Jessen 1966; Johanson et al. 2007; Andrews et al. 2006) but is unknown in Grossius (Schultze 1973) (Fig. 18). In 
Selenodus, a well-developed tabular pit line is absent, a condition also known in the stem osteichthyans Guiyu, Psarolepis and Achoania (Yu 1998; Zhu et al. 1999, 2001; Qiao \& Zhu 2010).

Anterior to the supratemporal, an intertemporal bone is usually found in sarcopterygians, carrying the anterior portion of the otoccipital lateral line canal. In Onychodus, the intertemporal (which normally flanks the parietals) is absent (Andrews et al. 2006), the junction between the supraorbital and infraorbital lateral line canal is thought to have occurred in soft tissue. In Strunius, an intertemporal also appears to be absent, the supratemporal directly contacting the supraorbital and the parietal (Jessen 1966). No intertemporal has been found in Selenodus. Among coelacanths, Miguashaia and Gavinia are the only actinistians to primitively retain an intertemporal (Cloutier 1996; Forey 1998; Long 1999) (Fig. 17C-D).

Lateral to the lateral line-carrying bones of the skull roof, an extratemporal bone is present in certain onychodonts. In Onychodus, it articulates with the tabular and the lateral extrascapular (Andrews et al. 2006) and with the supratemporal and tabular in Grossius, even carrying a branching of the lateral line canal from the supratemporal (Schultze 1973). Extratemporal bones are also known to occur in dipnomorphs (e.g., porolepiforms, Powichthys and Youngolepis) (Jarvik 1972; Jessen 1980; Chang 1982; Cloutier \& Schultze 1996) and tetrapodomorphs (e.g., Kenichthys, rhizodontids, and many 'osteolepiforms') (Chang \& Zhu 1993; Ahlberg 1991; Zhu \& Ahlberg 2004). An extratemporal bone was not retrieved in Selenodus, but its absence in actinopterygians (Gardiner 1984), actinistians (Forey 1998), lungfishes (Chang \& Yu 1983), certain 'osteolepiforms' (Borgen \& Nakrem 2016) and Strunius among onychodonts (Jessen, 1966) indicates its variable occurrence in osteichthyans.

\section{Jaw bones and dentition}

The upper and lower jaws of Selenodus are only partly preserved, but they display some phylogenetically interesting features. In onychodonts, the general outline of the maxilla with a narrow suborbital portion and a high posterior expansion is reminiscent of early actinopterygians (e.g., Cheirolepis, Mimipiscis, Moythomasia, Raynerius) (Gardiner 1984; Giles et al.2015), and represents the plesiomorphic condition of osteichthyans as seen in Guiyu (Zhu et al. 2009) and Psarolepis (Zhu et al. 1999). The reconstructed anterior portion of the maxilla of Selenodus more closely resembles the angular outline of Onychodus than the 
curvier one of Strunius (Fig. 16). Posteriorly, the deep, straight, and rounded rear of the maxilla of Selenodus is overally similar to that of Grossius, but it is not ventrally curved as in Onychodus and Strunius (Jessen 1966; Schultze 1973; Andrews et al. 2006). Posteriorly deep maxillae are primitive in osteichthyans and are known in psarolepids (e.g., Guiyu and Psarolepis) (Zhu et al. 1999, 2009), early actinopterygians (e.g., Cheirolepis) (Arratia \& Cloutier 1996), dipnomorphs (e.g., Youngolepis) (Chang 1981) and tetrapodomorphs (e.g., rhizodontids like Gooloogongia and certain 'osteolepiforms' like Gogonasus) (Long 1997; Johanson \& Ahlberg 2001). Styloichthys shows a posteriorly narrowing maxilla (Zhu \& Yu 2002) and other actinistians lack the maxilla altogether (Forey 1998) as do lungfishes (Janvier 1996). However, as opposed to actinopterygians, the maxillae of most sarcopterygians are straight and do not show a ventrally turned posterior portion, which is incipient in Cheirolepis (Arratia \& Cloutier 1996) (Fig. 17B) but more marked in Mimipiscis, Moythomasia, Howqualepis and Raynerius (Gardiner 1984; Long 1988; Giles et al. 2015). Onychodonts like Onychodus and Strunius retain this primitive condition of ventrally curved maxillae, present also in Guiyu (Fig. 17A) and Psarolepis (Zhu et al. 1999, 2009). However, in Strunius the teeth extend further back into the mandible articulation (Jessen 1966), a primitive condition for osteichthyans known in actinopterygians like Cheirolepis and Raynerius (Arratia \& Cloutier 1996; Giles et al.2015) as opposed to Onychodus and Selenodus in which the maxillary teeth do not reach the rear of the maxilla (Figs 16-17).

Upper and lower jaw dentition is highly variable among sarcopterygians, and it is currently difficult to propose evolutionary scenarios based on dental characters alone. In Selenodus, Strunius and Onychodus, a row of small teeth lateral to the main row is present in the maxilla as well as in the dentary (as evidenced in Selenodus and Onychodus by the occurrence of a hollow pulp cavity in the small denticles) grading into smaller tubercles on the labial side of the jawbones (Jessen 1966; Andrews et al. 2006). This accessory row of small teeth is present in the dentary of Luckeus (Young \& Schultze, 2005) but it is absent from the dentary of Bukkanodus (Johanson et al., 2007) and the maxilla of Qingmenodus (Lu $\&$ Zhu, 2010). Early actinopterygians (e.g., Cheirolepis, Mimipiscis, Moythomasia) (Gardiner, 1984; Arratia \& Cloutier, 1996), psarolepids (Guiyu, Achoania, Psarolepis) (Zhu \& Yu, 2004; Zhu et al. 2009) and other stem osteichthyans (Lophosteus, Andreolepis) (Botella et al., 2007) display the primitive condition with two tooth rows composed of a lingual main row of large teeth and a smaller secondary labial row of smaller teeth, occurrying both in the upper (premaxilla and maxilla) and lower jaw (dentary). Styloichthys and primitive actinistians have 
only a single row of dentary teeth (Jessen 1966; Forey 1998; Long 1999; Friedman, 2007), which can be considered as a synapomorphy of coelacanths; however the variable occurrence of secondary tooth rows in onychodonts hampers a more precise statement of their phylogenetic implications. Other sarcopterygians like porolepiforms, rhizodontids and certain 'osteolepiforms' have a single row of large teeth, although some variation can occur (e.g., accessory teeth are known in dipnomorphs like in Powichthys and in tetrapodomorphs like Eusthenopteron, Panderichthys and the early tetrapod Elginerpeton) (Jarvik 1944; Jessen 1980; Ahlberg \& Clack 1998).

One of the most remarkable features of onychodonts is the occurrence of parasymphysial plates carrying large, sigmoid tusks (granting them the accurate name of "dagger-toothed" fishes). Onychodus has large parasymphysial tooth plates with a massive and sigmoid fang whorl and two small accessory rows of denticles (Gross 1965; Andrews et al. 2006). Complete tooth whorls or isolated large tusks have been also described in Strunius, Grossius, Luckeus, and Qingmenodus (Jessen 1966; Schultze 1973; Young \& Schultze 2005; Lu \& Zhu 2010). The dental material of Selenodus is too incomplete or too small to assign any of the isolated teeth to the parasymphysial tooth whorl. Outside onychodonts, parasymphyseal teeth are known in several other sarcopterygians and constitute a primitive character of osteichthyans, as present in early dipnomorphs and basal actinopterygians, like Howqualepis (Long 1988). In porolepiforms (e.g., Porolepis, Glyptolepis, and Holoptychius) (Jessen, 1966; Jarvik, 1972) the teeth of the parasymphysial plates are generally arranged in several longitudinal rows and a great degree of variability in the number and distribution of rows occurs. Stem osteichthyans like Guiyu, Psarolepis and Achoania display large internasal cavities in the palate for the tips of putative parasymphysial tusks (Zhu \& Yu 2004), but dental plates are unknown in both of these taxa. The internasal cavities of Guiyu and Psarolepis are narrow and deep, resembling those of Onychodus (Qiao et al. 2010), whereas in Achoania they are shallower and oval-shaped, reminiscent of Powichthys and porolepiforms (Zhu \& Yu 2004), suggesting the occurrence in Guiyu and Psarolepis of more prominent and onychodont-like parasymphesal fangs while Achoania might have possess smaller plates, similar to those of porolepiforms. The puzzling Langdenia from the Lower Devonian of Vietnam displays a toothless area in the anterior tip of the dentary, similar to the condition of porolepiforms and onychodonts (Janvier \& Phuong 1999; Zhu \& Yu 2004). Many tetrapodomorphs carry large fangs in the anterior tip of the dentary, but no distinctitve and independent dental plates. Styloichthys has very reduced attachment areas for the 
parasympyseal dental plates (Friedman 2007) and other coelacanths do not possess distinctive dental parasymphysial plates, as do lungfishes.

\section{Dermal ornamentation and histology}

The ornamentation and microstructural organisation of the dermal bones in osteichthyans have important phylogenetic implications. The evolution of histological complexes (e.g., cosmine and ganoine) and odontogenic derivates (i.e., enamel and dentine) in vertebrates has been found to be more intricate and less restrictive than previously thought (e.g., Qu et al., 2016; Mondéjar-Fernández, 2018). Histological features should thus be viewed less as categorical and immobile innovations but rather as part of an evolutive histological continuum. Special care should be taken when describing dermal ornamentation in order to avoid statements that are usually not confirmed by histological data or by lack of comparative data from other taxa altogether.

The scales and dermal bones of onychodonts are variable in their ornamentation but histological data have been, until now, almost entirely lacking. In Bukkanodus, the surface of certain dermal bones displays numerous evenly spaced pores, which appears to superficially indicate the presence of cosmine, however unpublished thin sections failed to show the associated system of pore canals and distinct layer of enamel (Johanson et al. 2007:1040). The shiny and probably enamel-coated ethmoid of Qingmenodus displays smaller and more closely packed pores than Bukkanodus, again reminiscent of cosmine but no histological data has been published (Lu \& Zhu 2010). In Selenodus, large pores, similar in size to those of Bukkanodus, are present in numerous bones of the cheek, including the lateral rostral, anterior and posterior tectals, fragments of the lacrimal, postorbital and jugal (Fig. 2, 3). These pores are less numerous in the nasal series. In the skull roof, similar pores have also been identified mainly in the supratemporal but smaller ones also occur in the tabular and lateral extrascapular (Fig. 8). Such pores are also known in Onychodus where they are considered to be related to the course of the lateral line canal through the cheek and skull roof (Andrews $e t$ al. 2006), as in Selenodus. Pore clusters associated with the course of the lateral line are also known in porolepiforms (Jarvik 1972), Youngolepis (Chang 1982) and tetrapodomorphs (e.g., Osteolepis, Gyroptychius, Gogonasus) (Jarvik 1944; Long et al. 1997), but in these cases pores open through the outer enamel layer of the cosmine.

Dermal bones of the cheek and dentary display oval to rounded small tubercles in Selenodus, but, as opposed to the tubercles present in the scales, they do not overally posses a 
clearly depressed central region. In Onychodus, spoon-shaped tubercles are present in the dermal bones of $O$. sigmoides (Newberry 1857) but absent from $O$. obliquedentatus, $O$ jaeckeli and O.jandemarrai (Jessen 1966; Andrews et al. 2006). In Strunius and Grossius, dermal bones are unornamented (Jessen 1966) but in Grossius small flat weathered tubercules can be discernable under strong magnification (Schultze 1973). Tubercule ornamentation is reminiscent of other non-cosmine-covered early sarcopterygians like the actinistians Gavinia, in which the snout and lower jaw bones are ornamented by coarse, closely-spaced tubercules while the rest of the dermal bones and scales display wavy vermiform ridges (Long, 1999) and Miguashaia with small tubercules or patches of enamel sheath in the scales and dermal bones (Cloutier 1996; Forey et al. 2000). On the inner side of the jaws, a denticulated ornamentation of the prearticular and other palatal bones is widespread in osteichthyans (e.g., Jarvik 1980; Gardiner 1984). Prearticular denticles occur in onychodonts like Onychodus (Andrews et al. 2006) and Selenodus (Fig. 11) but differs from the longitudinal ridges present in Megamastax (Choo et al. 2014), Styloichthys (Zhu \& Yu 2002) and coelacanths (Millot \& Anthony 1958; Forey 1998; Friedman 2007).

The scales of all known onychodonts are rounded in shape except in Qingmenodus for which the scale shape is still unknown ( $\mathrm{Lu} \& \mathrm{Zhu} 2010)$. The exposed area of the scales is classically ornamented with characteristic pointy tubercles supposedly made of dentine capped with a thin enamel layer (Janvier 1996) and now evidenced in Selenodus (Fig. 14). The histological microstructure of these tubercules and of the scales in general is identical to that of the extant coelacanth Latimeria (Castanet et al. 1975; Meunier et al. 2008), probably representing a primitive shared condition of onychodonts and actinistians but due to the almost complete lack of histological knowledge on coelacanths, further histological data are needed to confirm it. Jessen (1966) described patches of cosmine occurrying in certain dermal bones in Strunius, but such assertions ought to be considered unreliable due to the absence of histological survey and the small size of the specimens (Mondéjar-Fernández 2018). The overlapped areas of the scales of Bukkanodus are ornamented by closely packed but distinct tubercule rows, with the apex pointing posteriorly, whereas the exposed area is ornamented with wide dentine ridges separated by grooves containing pores (Johanson et al. 2007). This ornamentation is puzzling considering the general condition found in onychodonts and early actinistians, in which the overlapped area is unornamented and the exposed area carries the pointy tubercules (e.g., Forey et al. 2000; Andrews et al.2006). Grossius deviates from this trend in that the tubercules occur in the overlapped area of the scales, whereas the exposed 
area is not ornamented (Schultze 1973), although this might be due to preservation issues. Spoon-shaped tubercules located at the edge between the overlapped and exposed areas are a plesiomorphic feature of sarcopterygians as present in onychodonts and actinistians (Forey 1998; Forey et al. 2000), and dipnomorphs (Ørvig 1957, 1969; Denison 1968; MondéjarFernández \& Clément 2012) whereas tetrapodomorphs display either a continuous layer of cosmine or a bony ornamentation composed of ridges or vermiculated, blunt tubercules (e.g., Jarvik 1980).

Absence of cosmine is a diagnostic feature of all known onychodonts. However, as Zhu \& Yu (2004) and Lu \& Zhu (2010) suggested a cosmine-covered fragment of a dentary from the Pragian of Yunnan (China) could belong to an onychodont. Lu \& Zhu (2010) described the ornamentation of the dermal bones of Qingmenodus as showing closely spaced tiny pores, but did not precised whether this ornamentation can be considered cosmine. Zhu \& Zhao (2005) also briefly mentioned a putative, yet unnamed, cosmine-covered onychodont from the Middle Devonian (Zhaotong Formation) of China. The suspected basal actinistian Styloichthys possess cosmine (Zhu \& Yu 2002; Friedman 2007; Gess \& Coates 2016), while other more derived coelacanths do not (e.g., Miguashaia, Gavinia) (Cloutier 1996; Long 1999). Cosmine is primitively present in all major sarcopterygians groups (e.g., all early dipnomorphs like Youngolepis, Powichthys, porolepiforms like Porolepis, dipnoans like Diabolepis, Uranolophus and Dipnorhynchus, and early tetrapodomorphs like Tungsenia and Kenichthys) (Mondéjar-Fernández 2018). Recent histological analyses confirm its occurrence in stem osteichthyans (psarolepids like Psarolepis, Achoania) (Zhu et al. 1999, 2001; Qu et al. 2013, 2016) and in the early actinopterygians Meemannia and Cheirolepis (Lu et al. 2016b). All subsequent members of each group of crown osteichthyans convergently lost cosmine throughout the Middle-Late Palaeozoic. It would thus not be surprising that, yet undiscovered basal onychodonts would show a cosmine covering that was later lost in younger and more derived forms.

Concerning the teeth, striated enamel is considered as a main synapomorphy of onychodonts, but its phylogenetic implications and distribution is questionable. The presence of ribs with a superficial chevron or herringbone pattern has been described in the parasymphysial tusks of numerous onychodonts: large ribs in Strunius, Luckeus and Qingmenodus, thinner in Onychodus and Grossius, and weakly developed in Bukkanodus (Gross 1956; Jessen 1966; Schultze 1973; Smith 1989; Andrews et al. 2006; Johanson et al. 2007; Lu \& Zhu 2010). However, diagnostic striae might be difficult to see in smaller, non 
parasymphysial teeth such as in the small isolated teeth of Selenodus (Fig. 14) and in an Early Devonian Chinese form, similar to Strunius (Zhu \& Janvier 2004), which shows a lack of striae on the dentary teeth. The lack of striated enamel was considered primitive for osteichthyans (e.g., Guiyu) (Zhu et al. 2009) but its presence has been observed in the actinopterygian Cheirolepis (Arratia \& Cloutier 1996; Meunier et al. 2018). In sarcopterygians, striated enamel is known to occur in rhizodontids (Jeffery 2003) and porolepiforms (Mondéjar-Fernández \& Janvier 2014).

Previous assumptions on the occurrence and distribution of plicidentine in osteichthyans have been recently challenged by the development of virtual histological study of the teeth of predatory fishes (e.g., Meunier et al. 2015a,b, 2018; Germain et al. 2016). The teeth of onychodonts have been widely described as unfolded and thus lacking plicidentine (e.g., Schultze 1969; Vorobyeva 1977; Andrews et al. 2006). Schultze (1969, p. 126-128, Fig. 26) illustrated cross sections of the bases of the symphysial tusks of Onychodus in which small plications of the orthodentine are visible at the base whereas the pulp cavity is free from osteodentine, later emphasised by Janvier (1996). However, this condition was not gathered among the different plicidentine morphotypes defined by Schultze (1969) and hence the teeth of the onychodonts were said to lack plicidentine, as those of actinistians. However, a similar kind of dentine folds have been described in the fangs of Latimeria (Meunier et al.2015b) and a new term has been coined to account for this simple kind of plicated dentine: simplexodont plicidentine. Due to their similarity, the folds of the dentine in Onychodus could be confidently assigned to the simplexodont condition as displayed in Latimeria. The same scenario applies for Selenodus, in which minute folds only occur at the base of the teeth, the rest of the tooth showing a hollow pulp cavity, not filled with osteodentine and with smooth inner walls of orthodentine (Fig. 10B). Other types of more complex plicidentine (i.e., dendrodont, eusthenodont, polyplocodont plicidentine) are known in sarcopterygians (e.g., porolepiforms, Youngolepis, Powichthys, rhizodontids, 'osteolepiforms' and early tetrapods) (Schultze 1970; Chang \& Smith 1992), and thus it was considered that plicidentine was a synapomorphy of rhipidistians (Ahlberg 1991). However, simple plicated dentine (simplexodont plicidentine) has been described in the stem osteichthyan Psarolepis (Yu 1998; Zhu et al. 1999) and in the actinopterygian Cheirolepis (Meunier et al. 2018), thus suggesting that plicidentine might be a primitive feature of all osteichthyans. Nevertheless, whether the occurrence of plicidentine bears a strong phylogenetic signal or represents a convergent response to predatory constraints in osteichthyans needs further inquiry. 


\section{Endoskeletal elements}

The lesser number of endoskeletal elements retrived from the fossil material of Selenodus, in comparison with the well represented dermocranium evidences a probable reduced endoskeletal ossification rate, as in other onychodonts (e.g., Bukkanodus; Onychodus) (Andrews et al.2006; Johanson et al. 2007). A poorly ossified neurocranium is considered one of the main reasons for the generally disarticulated state of preservation of onychodotid remains since a poor ossification of the braincase might be associated with the loose connection of the dermal skull bones, causing them to disarticulate and scatter after death (Janvier 1996), a scenario also proposed for Onychodus and Bukkanodus (Andrews et al. 2006; Johanson et al. 2007) and now applicable to Selenodus.

In the skull, the mainly cartilaginous state of the braincase might similarly apply to the visceral skeleton and the gills arches. Of the branchial series, only two ceratobranchials have been retrieved in Selenodus, but their position in the gill series is difficult to ascertain (Fig. 10). Among onychodonts, branchial elements are solely known in Onychodus (Andrews et al. 2006) and the exact number of branchial arches has not been clearly counted. Five branchial arches are primitively present in gnathostomes (Janvier 1996) and probably also represent the plesiomorphic condition in sarcoptergyians, where five arches are known in coelacanths (e.g., Rhabdoderma, Macropoma, Latimeria) (Forey 1998) and porolepiforms (e.g., Glyptolepis, Laccognathus) (Jarvik 1980; Kanyukin 2006). Devonian dipnoans like Chirodipterus and Griphognathus (Miles 1977) have four gill arches but it probably consitutes a reduction from a primitive five-arch condition in dipnomorphs. Tetrapodomorphs might primitively bear only four gill arches (e.g., Eusthenopteron, Medoevia, Gogonasus, Mandageria (Jarvik 1954 ; Lebedev 1995 ; Long et al. 1997 ; Johanson \& Ahlberg 1997; Witzmann 2013).

The general structure of the ceratobranchials in Selenodus ressembles the ceratobranchials of the dipnoan Griphognathus in which the proximal ends were pierced by a foramen for the passage of the nerve and vessel (Miles 1977). The extremely fragile and badly preserved distal portion of both bones makes the occurrence of a similar foramen in Selenodus impossible to ascertain. Both extremities of the ceratobranchials were probably capped by a large cartilage head, as described in coelacanths like Latimeria (Millot \& Anthony 1958; Forey 1998). Elongate ceratobranchials indicate a well developed lower half of the branchial arch in Selenodus, ressembling porolepiforms (Jarvik 1972, 1980), lungfishes (Miles 1977), and early tetrapods like Acanthostega (Coates \& Clack 1991). The dorsal elements of the 
branchial series, namely the epi- and pharyngobranchials are unknown in Selenodus but their absence might be due to their cartilaginous nature, a condition also observed in many other sarcopterygians (coelacanths, dipnomorphs and tetrapodomorphs) (e.g., Nelson 1969; Rosen et al. 1981; Forey 1998).

\section{Phylogenetic analysis}

The monophyly of the Onychodontida has been discussed (and generally accepted) by numerous studies (e.g., Jessen 1967; Andrews 1973; Ahlberg 1991; Janvier 1996; Zhu et al. 2002, 2009). However, in many of these studies, only two taxa have been considered as representatives of the onychodonts, namely Strunius and Onychodus. In all cases were these two forms have been used as the sole representatives of the Onychodontida, monophyly has been recovered (except in Friedman 2007). Moreover, in recent analyses, the position of onychodonts as the sister group of coelacanths has been solidely established (e.g., Lu \& Zhu 2010; Lu et al. 2016a,b, 2017; Clement et al. 2018). However, when further taxa (e.g., Qingmenodus, Grossius and Bukkanodus) are taken into account to investigate onychodont interrelationships, both whithin the group and among sarcopterygians, the supposedly wellestablished monophyly is challenged (e.g., Lu et al. 2016a). The addition of Selenodus enables to more deeply understand the puzzling evolution of onychodonts, discuss their interrelationships within sarcopterygians, and to test evolutionary scenarios and character combinations among early osteichthyans. Since all the fossil material of Selenodus comes from a single individual, it constitutes an ideal representative for inclusion in a phylogenetic analysis that avoids any uncertainties surrounding attribution of isolated skeletal elements to single species or intraspecific variability.

In order to assess the phylogenetic position of Selenodus, the data matrix assembled by Lu et al. (2016a) on their survey of onychodonts based on Qingmenodus was used. The data matrix thus included 38 taxa and 242 characters, comprising characters from the dermoand neurocranium, postcranial skeleton and histology of numerous osteichthyans.

Onychodonts were abundantly represented by the most completely-known genera: Bukkanodus, Strunius, Qingmenodus, Grossius and Onychodus (only Luckeus was excluded due to the poorly representative material). Ligulalepis, Dialipina and the actinopterygians Meemannia, Cheirolepis, Mimipiscis and Moythomasia were designated as outgroup. Character data entring and formatting were performed on Mesquite (version 3.31) (Maddison $\&$ Maddison 2015). The matrix was subjected to a maximum parsimony analysis in PAUP 
(version 4.0a) (Swofford 2003) using the heuristic algorithm and 1000 bootstraps replicates with 100 random sequence addition by replicate. All characters were treated as unordered and weighthed equally. The analyses gave 980 equally parsimonious trees of 549 steps (consistency index, $\mathrm{CI}=0,5046$; retention index, $\mathrm{RI}=0,7486$ ).

The strict consensus tree (Fig. 19A) confirms the position of onychodonts as the sister group of coelacanths, within the crown sarcopterygians. The strict consensus places Selenodus among onychodonts in an unresolved position at the base of the group, forming a polytomy with Bukkanodus, two onychodont clades (gathering Strunius and Qingmenodus and Onychodus and Grossius), and the coelacanths. The 50\% majority consensus tree (Fig. 19B) resolves Bukkanodus as the sister group of the clade including Selenodus, onychodonts, and coelacanths. Selenodus is excluded from a monophyletic Onychodontida (sensu Lu et al. 2016a and comprising here the Strunius-Qingmenodus and Onychodus-Grossius clades). As in the previous analysis by Lu et al. (2016a), the interrelationships of early coelacanths (Miguashaia, Gavinia and Euporosteus) are not fully resolved ; the interrelationships within the crown sarcopterygians are not affected by the inclusion of Selenodus to the analysis. However, as opposed to previous analyses, Strunius is no longer the most basal onychodont but is retrieved as the sister group of Qingmenodus. The close relationship between Onychodus and Grossius is again confirmed.

A monophyletic Onychodontida including Selenodus is neither retrieved in the strict consensus nor in the $50 \%$ majority rule trees. A similar result was obtained with the inclusion of Bukkanodus by Lu et al. (2016a) but in this case onychodonts, with the exclusion of Bukkanodus, were found monophyletic. Bukkanodus and Selenodus appear thus as successive sister groups of onychodonts and actinistians. This result can be explained by an incomplete and disarticulate preservation of mainly dermocranial remains and lack of key features in Bukkanodus (around 90\% of missing data). The material of Selenodus is substantially more complete (only $80 \%$ of missing data), belonging to a single individual, and stratigraphically younger than Bukkanodus; accordingly a more cronward position among onychodonts is more likely. However, the lack of phylogenetic information from character rich anatomical systems (such as the neurocranium, jaw symphysis and skull roof) hampers a reliable assignement to both Bukkanodus and Selenodus.

A close relationship between onychodonts and actinistians has become a recurrent result in recent studies of sarcopterygian interrelationships (e.g., Zhu et al. 1999, 2001, 2006, 2009; Botella et al. 2007; Lu \& Zhu 2010; Lu et al. 2016a,b, 2017; Clement et al. 2018). The 
onychodont-actinistian clade is a meaningful component in crown sarcopterygian systematics and parallels the rhipidistian radiations of dipnomorphs and tetrapodomorphs from the Early Devonian onwards. It has been shown that Bukkanodus can either be included in the Onychodontida as its most basal member (sensu Lu \& Zhu 2010) or be excluded from the clade as the sister group of onychodonts and coelacanths (Lu et al. 2016a, this study). Similarly, Selenodus is more crownwardly reconstructed than Bukkanodus, but fails to cluster here in a monophyletic Onychodontida (sensu Lu et al. 2016a and comprising Strunius, Qingmendous, Onychodus and Grossius). The recovery of an onychodont-coelacanth clade in the present analysis and the position of Bukkanodus and Selenodus whithin this clade as successive sister groups of the rest of onychodonts and actinistians gives further support to the hypothesis that considers onychodonts as a paraphyletic ensemble of stem actinistians. New discoveries and redescriptions of onychodonts might show that the Onychodontida may well be a clade and the sister group of Actinistia, irrespective of the inclusion of Bukkanodus among onychodonts.

\section{Paleobiogeographical implications}

The earliest occurrences of onychodonts, or enigmatic early sarcopterygians reminiscent of onychodonts, are known from the Late Silurian-Early Devonian of China and South-East Asia (the paleogeographical province from the northern margin of Gondwana known as the South China block) (Zhu \& Janvier 1994, Janvier \& Phuong 1999, Lu \& Zhu 2010). These include a cosmine-covered dentary tentatively attributed to onychodonts (Zhu \& Yu 2004) and a lower jaw fragment, probably belonging to Qingmenodus (Lu \& Zhu 2010), both from the Lockovian and Pragian of China respectively. Langdenia campylognatha from the Lochkovian of Vietnam (Janvier \& Phuong 1999) is known from fragmentary jaw remains covered with cosmine described as displaying certain onychodont features but was rather tentatively assigned to the Dipnomorpha. Bukkanodus occurs in the Pragian of Australia along with the earliest coelacanth Eoactinistia foreyii (Johanson et al. 2006), indicating that the earliest stages of the onychodont and coelacanth radiation occurred in East Gondwana (Zhu et al. 2012). By the Middle Devonian onychodonts had achieved a global distribution, being found throughout Euramerica (e.g., North America and Europe) and the northern margin of Gondwana (e.g., Middle East) mainly during the Frasnian.

Selenodus from the Eifelian (Middle Devonian) is the earliest onychodont found in Africa and occupies an interesting paleogeographical position, bridging the North African 
coastline (northern margin of Gondwana) with the European and North American fossils sites (southern margin of Euramerica) (e.g., Golonka, 2000; Scotese, 2001). It is also the onychodont found in the most austral latitudes of the southern paleohemisphere (Fig. 1C). The absence of onychodont remains in South America might suggest that the main dispersal route used by onychodonts from East Gondwana (Australia and China) was through the socalled South Route across the Middle-East, Armorica (comprising Spain), and northern Africa into Euramerica (Zhao \& Zhu 2010). However, the absence of onychodont remains in South America and their poor representation in Africa may be due to incomplete sampling of Devonian sites (Olive et al. 2019). Onychodont remains are common among the well-studied Frasnian (Late Devonian) faunas of Euramerica and Gondwana, usually in the form of disarticulated and badly preserved fragments attributed to Onychodus or Strunius (e.g., Gross 1933, 1956; Janvier \& Martin 1979) attesting of their cosmopolitanism by the Late Devonian. The youngest onychodont material comes from the Fammenian (Late Devonian) of Latvia (Blieck et al. 1988). Carboniferous occurrences of isolated teeth in North America (Schultze 1973) have been discarded as onychodont remains and belong more likely to rhizodontids, which also show striated enamel in their large sigmoid teeth (Janvier 1996).

\section{CONCLUSION}

More than 40 years after its discovery (Lehman 1976), a new onychodont species from the Middle Devonian (Eifelian) of Morocco is redescribed and named Selenodus aquesbiae n. gen. and sp. Despite previous descriptions and hesitant taxonomical attribution of the material (Aquesbi, 1988), its confident assignement to a new genus and species of onychodont is confirmed by the particular arrangement of the cheek bones and the shape of the maxilla. The ornamentation and articulation surfaces allowed the partial reconstruction the snout, cheek and skull roof and confirm that all fossil remains belong to a single individual. Selenodus shares some similiarities with Late Devonian onychodonts like Onychodus and Grossius like a deep and straight posterior portion of the maxilla and a somewhat narrow postparietal shield. Potential symplesiomorphies within onychodonts include the presence of numerous pores in the cheek and skull roof, the occurrence of small denticles lateral to the main row of teeth in the dentary and maxilla, weakly developed striated enamel in the teeth, and pointy tubercules in the scales and dermal bones capped with enamel. 
Selenodus represents the first occurrence of onychodonts in Africa and the earliest onychodont known from the northern margin of Gondwana. As such, it adds new information to the diversity and evolution of this puzzling group of early sarcopterygians. However, the incomplete preservation of certain key features precludes establishing a reliable phylogenetic position. The phylogenetic placement of Selenodus challenges the supposedly admitted monophyly of the Onychodontida while the close relationship between onychodonts and coelacanths is here further strengthened among crown sarcopterygians. Further material from early forms (like Bukkanodus and Selenodus) and new, thorough investigations on wellpreserved material (like Grossius) are needed to better evaluate onychodont interrelationships and unravel their role in the early steps of osteichthyan evolution.

\section{ACKNOWLEDGEMENTS}

I warmly thank Gaël Clément, Philippe Janvier, Daniel Goujet, Hervé Lelièvre, Alan Pradel, and Guillaume Lecointre (MNHN, Paris), Per Ahlberg (Uppsala University), Zerina Johanson (NHM, London), Jenny Clack (University of Cambridge), John Long (Flinders University), Jing Lu (IVPP, Beijing), Matt Friedman (University of Michigan), Sam Giles (University of Oxford), Martin Brazeau (Imperial College, London), Martin Rücklin (Naturalis Biodiversity Center, Leiden), Pierre Guériau (University of Lausanne), Fabrice Fack and Vincent Dupret for fruitful discussions on sarcopterygian diversity, onychodont anatomy and phylogenetic analyses. Florian Witzmann (MfN, Berlin) and Zerina Johanson (NHM) generously provided access to fossil material under their care. Séverin Morel (MNHN) prepared the thin sections, and François Meunier and Damien Germain (MNHN) allowed microscope access. SEM pictures were taken by Philippe Loubry (MNHN) and Marc Herbin and Zora Gabsi (MNHN) assisted with the acquisition of X-rays images. The constructive remarks of two anonymous reviewers improved the paper. I also acknowledge the funding by the Société des Amis du Muséum national d'Histoire naturelle for the study of the collections at the Museum für Naturkunde (MfN), Berlin. Per Ahlberg (Uppsala University) and Paulo Brito (Universidade do Estado do Rio de Janeiro) kindly supported my application to a Synthesis grant to study the Onychodus collections at the Museum of Natural History (NHM), London.

\section{REFERENCES}


Ahlberg, P. E. 1991. A re-examination of sarcopterygian interrelationships, with special reference to the porolepiformes. Zoological Journal of the Linnean Society, 103, 241287.

Ahlberg, P. E. \& Clack, J.A. 1998. Lower jaws, lower tetrapods - a review based on the Devonian genus Acanthostega. Transactions of the Royal Society of Edinburgh: Earth Sciences, 89, 11-46.

Andrews, S. M. 1973. Interrelationships of crossopterygians. Pp. 138-177 in P. H. Greenwood, R. S. Miles \& C. Patterson (eds) interrelationships of fishes. Academic Press, London.

Andrews, S. M. 1985. Rhizodont crossopterygian fish from the Dinantian of Foulden, Berwickshire, Scotland, with a re-evalutaion of the group. Transactions of the Royal Society of Edinburgh, Earth Sciences, 76, 67-95.

Andrews, S. M., Long, J. A., Ahlberg, P. E., Barwick, R. \& Campbell, K. 2006. The structure of the sarcopterygian Onychodus jandemarrai n. sp. from Gogo, Western Australia: with a functional interpretation of the skeleton. Transactions of the Royal Society of Edinburgh, 96, 197-307.

Aquesbi, N. 1988. Etude d'un onychodontiforme (Osteichthyes, Sarcopterygii) du Dévonien Moyen (Eifélien) du Maroc. Bulletin du Muséum national d'Histoire naturelle, 10, 181196.

Arratia, G. \& Cloutier, R. 1996. Reassessment of the morphology of Cheirolepis canadensis (Actinopterygii). Pp. 165-197 in H.-P. Schultze \& R. Cloutier (eds). Devonian fishes and plants of Miguasha, Quebec, Canada. Verlag Dr. Friedrich Pfeil, München.

Becker, T. R., Jansen, U., Plodowski, G., Schindler, E., Aboussalam, S. Z. \& Weddige, K. 2004. Devonian litho-and biostratigraphy of the Dra Valley area-an overview. Devonian of the western Anti Atlas : correlations and events. Documents de l'Institut Scientifique de Rabat, 19, 3-18.

Blieck, A., Golshani, F., Goujet, D., Hamdi, A., Janvier, P., Mark-Kurik, E. \& Martin, M. 1980. A new vertebrate locality in the Eifelian of Khush-Yeilagh formation, Eastern Alborz, Iran. Palaeovertebrata, 9 (5), 133-154.

Blieck, A., Mark-Kurik, E. \& Marss, T. 1988. Biostratigraphical correlations between Siluro-Devonian invertebrate-dominated and vertebrate-dominated sequences: the East Baltic example. Pp. 579-87 in N. J. Mcmillan, A. F. Embry \& D. J. Glass (eds.) 
Paleontology, Paleoecology and Biostratigraphy (Devonian of the World. Volume III. Canadian Society of Petroleum Geologists, Calgary, Alberta.

Borgen, U. J. 1983. Homologizations of skull roofing bones between tetrapods and osteolepiform fishes. Palaeontology, 26 (4), 735-753.

Borgen U. J. \& Nakrem H.A. 2016. Morphology, phylogeny and taxonomy of osteolepiform fish. Fossils and Strata, 61, 1-514.

Botella, H., Blom, H., Dorka, M., Ahlberg, P. E. \& Janvier, P. 2007. Jaws and teeth of the earliest bony fishes. Nature, 448, 583-586.

Campbell, K. S. W. \& Barwick, R. E. 2006. Morphological innovation through gene regulation: an example from the Devonian onychodontiform fish. International Journal of Developmental Biology, 50, 371-375.

Castanet J., Meunier F., Bergot C. \& François Y. 1975. Données préliminaires sur les structures histologiques du squelette de Latimeria chalumnae. I - Dents, écailles, rayons de nageoires. Colloque International du CNRS, «Problèmes actuels de Paléontologie. Évolution des Vertébrés », 1973, 159-168.

Chang M.-M. 1982. The braincase of Youngolepis, a Lower Devonian crossopterygian from Yunnan, southwestern China. Ph.D. dissertation, Stockholm University, Stockholm, Sweden. 113 pp.

Chang M.-M. \& Smith M.-M. 1992. Is Youngolepis a Porolepiform? Journal of Vertebrate Paleontology, 12 (3), 294-312.

Chang, M.-M. \& Yu, X. 1984. Structure and phylogenetic significance of Diabolichthys speratus gen. et sp. nov., a new dipnoan-like form from the Lower Devonian of Eastem Yunnan, China. Proceedings of the Linnean Society of New South Wales, 107, 171-184.

Chang, M.-M. \& Zhu, M. 1993. A new Middle Devonian osteolepidid from Quijing, Yunnan. Memoirs of the Association of Australasian Palaeontologists, 15, 183-198.

Choo, B., Long, J. A. \& Trinajstic, K. 2009. A new genus and species of basal actinopterygian fish from the Upper Devonian Gogo Formation of Western Australia. Acta Zoologica, Supplement, 90, 194-210.

Choo B., Zhu M., Zhao W., Jia L. \& Zhu Y.A. 2014. The largest Silurian vertebrate and its palaeoecological implications. Scientific reports, 4, 5242.

Clement, A. M., King, B., Giles, S., Choo, B., Ahlberg, P. E., Young, G. C. \& Long, J. A. 2018. Neurocranial anatomy of an enigmatic Early Devonian fish sheds light on early osteichthyan evolution. eLife, 7. 
Cloutier, R. 1996. The primitive actinistian Miguashaia bureaui Schultze (Sarcopterygii). Pp. 227-247 in H.-P. Schultze \& R. Cloutier (eds). Devonian fishes and plants of Miguasha, Quebec, Canada. Verlag Dr. Friedrich Pfeil, München.

Cloutier, R. \& Ahlberg P. E. 1995. Sarcopterygian interrelationships: how far are we from a phylogenetic consensus? Geobios, Memoir Special 19, 241-248.

Cloutier, R. \& Ahlberg P. E. 1996. Morphology, characters, and the interrelationships of basal sarcopterygians. 325-337 in Stiassny, M. L. J., L. R. Parenti \& G. D. Johnson (eds.). Interrelationships of Fishes. Academic Press, London.

Cloutier, R. \& Schultze, H.-P. 1996. Porolepiform fishes (Sarcopterygii). Pp. 248-270. in H.P. Schultze \& R. Cloutier (eds). Devonian fishes and plants of Miguasha, Quebec, Canada. Verlag Dr. Friedrich Pfeil, München.

Coates, M. I. \& Clack, J. A. 1991. Fish-like gills and breathing in the earliest known tetrapod. Nature, 352, 234-236.

De Pomeroy, A. 1995. Australian Devonian fish biostratigraphy in relation to conodont zonations. Courier Forschungsinstitut Senckenberg, 182, 475-486.

De Pomeroy, A. 1996. Biostratigraphy of Devonian microvertebrates from the Broken River region, north Queensland. Records of the Western Australian Museum, 17; 417-437.

Denison, R. H. 1968. The evolutionary significance of the earliest known lungfish Uranolophus. Pp. 247 - 257 in Ørvig, T. (ed.). Current Problems of Lower Vertebrate Phylogeny, Proceedings of the Fourth Nobel Symposium. Almqvist and Wiksell, Stockholm, Sweden.

Forey, P. L. 1998. History of the Coelacanth Fishes. Chapman and Hall, London. 419 pp.

Forey P., Ahlberg P. E., Luksevics E. \& Zupins I., 2000. A new coelacanth from the Middle Devonian of Latvia. Journal of Vertebrate Paleontology, 20 (2), 243-252.

Friedman, M. 2007. Styloichthys as the oldest coelacanth: implications for early osteichthyan interrelationships. Journal of Systematic Palaeontology, 5, 289-343.

Gai, Z., Yu, X. \& Zhu, M. 2017. The evolution of the zygomatic bone from Agnatha to Tetrapoda. The Anatomical Record, 300 (1), 16-29.

Gardiner, B. G. 1984. The relationships of the palaeoniscid fishes, a review based on new specimens of Mimia and Moythomasia from the Upper Devonian of Western Australia. Bulletin of the British Museum (Natural History): Geology, 37, 173-428.

Germain, D., Mondejar-Fernandez, J. \& Meunier, F. J. 2016. The detection of weakly developed plicidentine in teleost teeth using 3D tomography. Cybium, 40 (1), 75-82. 
Gess, R. W. \& Coates, M. I. 2016. Fossil juvenile coelacanths from the Devonian of South Africa shed light on the order of character acquisition in actinistians. Zoological Journal of the Linnean Society, 175 (2), 360-383.

Giffin, E. B. 1980. Devonian vertebrates from Australia. Postilla, 180, 1-15.

Giles, S., Darras, L., Clément, G., Blieck, A. \& Friedman, M. 2015. An exceptionally preserved Late Devonian actinopterygian provides a new model for primitive cranial anatomy in ray-finned fishes. Proceedings of the Royal Society B: Biological Sciences, 282 (1816), 20151485.

Golonka, J. 2000. Cambrian-Neogene plate tectonic maps. Wydavnictwa Universytetu Jagiellonskiego, Kraków b Wydawn, 125 pp.

Gross, W. 1933. Die Wirbeltiere des rhenischen Devons. Abhandlungen der Preussischen Geologischen Landesanstalt, 154, 1-81.

Gross, W. 1956. Über Crossopterygier und Dipnoer aus dem baltischen Oberdevon im Zusammenhang einer vergleichenden Untersuchung des Porenkanalsystems paläozoischer Agnathen und Fische. Kungliga Svenska Vetenskapsakademiens Handlingar, $4^{\circ}$ Serien, 5, 1-140.

Gross, W. 1965. Onychodus jaekeli Gross (Crossopterygii, Oberdevon), Bau des Symphysenknochens und seiner Zähne. Senckenbergiana Lethaea, 46a, 123-131.

Hollard, H. 1974. Recherches sur la stratigraphie des formations du Dévonian Moyen, de l'Emsien Supérieur au Frasnien, dans le Sud de Tafilalt et dans le Ma'der (Anti-Atlas oriental). Notes du Service Géologique du Maroc, 36 (264), 7-68.

Hollard, H. 1977. Le Dévonien du Maroc et du Sahara Nord-Occidental. Pp. 203-244 in Oswald, D. H. (ed.), International symposium on the Devonian system. Calgary.

Hollard , H. 1978. Corrélations entre niveaux à brachiopodes et à goniatites au voisinage de la limite Dévonien inférieur - Dévonien moyen dans les plaines du Dra (Maroc présaharien). Newsletters on Stratigraphy, 7 (1): 8-25.

Hollard, H. 1981. Principaux caractères des formations dévoniennes de 1'Anti-Atlas. Tableaux de corrélations du Silurien et du Dévonian de l'Anti-Atlas. Notes du Service Géologique du Maroc, 42 (308), 15-22.

Hussakof, L. \& Bryant, W. L. 1918. Catalog of the fossil fishes in the museum of the Buffalo Society of Natural Sciences. Buffalo Society of Natural Sciences Bulletin, 12, $1-198$. 
Huxley, T. H. 1880. On the application of the laws of evolution to the arrangement of the vertebrata, and more particularly of the mammalia. Proceedings of the Zoological Society, London. 1880, 649-661.

Janvier, P. 1996. Early Vertebrates. Clarendon Press, Oxford. 393 pp.

Janvier, P. \& Martin, M. 1979. Les vertébrés dévoniens de l'Iran central. IICoelacanthiformes, Struniiformes, Ostéolépiformes. Geobios, 4, 497-511.

Janvier, P. \& Phuong, T. H. 1999. Les vertébrés (Placodermi, Galeaspida) du Dévonien inférieur de la coupe de Lung C6-Mia Le, province de Ha Giang, Vietnam, avec des données complémentaires sur les gisements a vertébrés du Dévonien du Bac Bo oriental. Geodiversitas, 21, 33-67.

Jarvik, E. 1944. On the dermal bones, sensory canals and pitlines of the skull in Eusthenopteron foordi, with some remarks on Eusthenopteron säve-soderberghi. Kungliga Svenska Vetenskapsakademiens Handlingar, 21 (3), 1-48.

Jarvik, E. 1954. On the visceral skeleton in Eusthenopteron foordi, with a discussion of the parasphenoid and palatoquadrate in fishes. Kungliga Svenska Vetenskapsakademiens Handlingar, 4 (5), 1-104.

Jarvik, E. 1966. Remarks on the structure of the snout in Megalichthys and certain other rhipidistid crossopterygians. Arkiv för Zoologi, 19, 41-98.

Jarvik E. 1972. Middle and Upper Devonian Porolepiformes from East Greenland with special reference to Glyptolepis groenlandica n. sp., and a discussion on the structure of the head in the Porolepiformes. Meddelelser on Grønland, 187 (2), 1-307.

Jarvik, E. 1980. Basic Structure and Evolution of Vertebrates, Vol. 1. Academic Press, London. 575 pp.

Jeffery, J. E. 2003. Mandibles of rhizodontids: anatomy, function and evolution within the tetrapod stem-group. Transactions of the Royal Society of Edinburgh: Earth Sciences, 93, 255-276.

Jeffery, J. E. 2012. Cranial morphology of the Carboniferous rhizodontid Screbinodus ornatus (Osteichthyes: Sarcopterygii). Journal of Systematic Palaeontology, 10 (3), 475-519.

Jessen, H. L. 1966. Die Crossopterygier des Oberen Plattenkalkes (Devon) der Bergisch Gladbach-Paffrather Mulde (Rheinischer Schiefergebirge) unter Berücksichtigung von amerikanischem und europaischem Onychodus Material. Arkiv för Zoologi, 18 (2), 305389. 
Jessen H. L. 1967. The position of the Struniiformes Strunius and Onychodus among the crossopterygians. Colloques Internationaux du Centre National de la Recherche Scientifique, 163: 173-180.

Jessen, H. L. 1980. Lower Devonian Porolepiformes from the Canadian Arctic with special reference to Powichthys thorsteinssoni Jessen. Palaeontographica Abteilung (A), 167, $180-214$.

Johanson, Z. \& Ahlberg, P. E. 1997. New tristichopterid (Osteolepiformes: Sarcopterygii) from the Mandagery Sandstone (Famennian) near Canowindra, N.S.W. Transactions of the Royal Society of Edinburgh: Earth Sciences, 88, 37-68.

Johanson, Z. \& Ahlberg, P. E. 1998. A complete primitive rhizodont from Australia. Nature, 394: $569-572$.

Johanson, Z. \& Ahlberg, P. E. 2001. Devonian rhizodontids and tristichopterids (Sarcopterygii; Tetrapodomorpha) from East Gondwana. Transactions of the Royal Society of Edinburgh: Earth Sciences, 92, 43-37.

Johanson, Z., Long, J. A., Talent, J. A., Janvier, P. \&Warren, J.W. 2006. Oldest coelacanth, from the Early Devonian of Australia. Biology Letters, 2, 443-446.

Johanson, Z., Long, J. A., Talent, J. A., Janvier, P. \& Warren J. W. 2007. New onychondontiform (Osteichthyes; Sarcopterygii) from the Lower Devonian of Victoria, Australia. Journal of Paleontology, 81 (5), 1031-1043.

Kanyukin, A. A. 2006. Hyobranchial skeleton and hypobranchial muscles of rhipidistians. Paleontological Journal, 40 (3), 297-311.

Lebedev, O.A. 1995. Morphology of a new osteolepidid fish from Russia. Bulletin Museum National d'Histoire Naturelle, Paris, 4e series 17, 287-341.

Lehman, J. P. 1976. Nouveaux poissons fossiles du Dévonien du Maroc. Annales de Paléontologie (Vertébrés), 62 (1), 1-34.

Lelièvre, H. 1984. Antineosteus lehmani n.g., n. sp., nouveau brachythoraci du Dévonien inférieur du Maroc présaharien. Remarques sur la paléobiogéographie des homostéidés de l'Emsien. Annales de paléontologie, 70 (2), 115-158.

Lindley, I. D. 2002. Acanthodian, onychodont and osteolepidid fish from the middle-upper Taemas Limestone (Early Devonian), Lake Burrinjuck, New South Wales. Alcheringa: An Australasian Journal of Palaeontology, 26 (1), 103-126.

Long, J. A. 1988. New palaeoniscoid fishes from the Late Devonian and early Carboniferous of Victoria. Memoir of the Australasian Association of Palaeontologists, 7, 1-64. 
Long, J. A. 1989. A new rhizodontiform fish from the Early Carboniferous of Victoria, Australia, with remarks on the phylogenetic position of the group. Journal of Vertebrate Paleontology, 9 (1), 1-17.

Long, J. A. 1991. Arthrodire predation by Onychodus (Pisces, Crossopterygii) from the Devonian Gogo Formation, Western Australia. Records of the Western Australian Museum, 15, 479-481.

Long, J. A. 1999. A new genus of fossil coelacanth (Osteichthyes: Coelacanthiformes) from the Middle Devonian of southeastern Australia. Records of the Western Australian Museum, Supplement, 57, 37-53.

Long, J. A. 2001. On the relationships of Psarolepis and the onychodontiform fishes. Journal of Vertebrate Paleontology, 21 (4), 815-820.

Long, J. A. 2011. The rise of fishes: 500 million years of evolution. The Johns Hopkins University Press, Baltimore, USA. 287 pp.

Long, J. A., Barwick, R. E. \& Campbell, K. S. W. 1997. Osteology and functional morphology of the osteolepiform fish Gogonasus andrewsae Long, 1985, from the Upper Devonian Gogo Formation, Western Australia. Records of the Western Australian Museum, Supplement 53, 1-89.

Lu, J.\& Zhu, M. 2010. An onychodont fish (Osteichthyes, Sarcopterygii) from the Early Devonian of China, and the evolution of the Onychodontiformes. Proceedings of the Royal Society B, 277, 293-299.

Lu, J., Zhu, M., Long, J. A., Zhao, W., Senden, T. J., Jia, L. \& Qiao, T., 2012. The earliest known stem-tetrapod from the Lower Devonian of China. Nature Communications, $\mathbf{3}$, 1160 .

Lu, J., Zhu, M., Ahlberg, P. E., Qiao, T., Zhu, Y. A., Zhao, W. \& Jia, L., 2016a. A Devonian predatory fish provides insights into the early evolution of modern sarcopterygians. Science advances, 2 (6), p.e1600154.

Lu, J., Giles, S., Friedman, M., Den Blaauween, J. L. \& Zhu, M., 2016b. The oldest actinopterygian highlights the cryptic early history of the hyperdiverse ray-finned fishes. Current Biology, 26 (12), 1602-1608.

Lu, J., Giles, S., Friedman, M. \& Zhu, M. 2017. A new stem sarcopterygian illuminates patterns of character evolution in early bony fishes. Nature communications, 8, 1932.

Maddison, W. P. \& Maddison, D. R. 1999. MacClade: Analysis of phylogeny and character evolution. Sinauer Associates, Sunderland, Massachusetts. 
Mann, A., Rudkin, D., Evans, D. C. \& Laflamme, M. 2017. A large onychodontiform (Osteichthyes: Sarcopterygii) apex predator from the Eifelian-aged Dundee Formation of Ontario, Canada. Canadian Journal of Earth Sciences, 54 (3), 233-241.

Meunier, F. J., Erdmann, M. V., Fermon, Y. \& Caldwell, R. L. 2008. Can the comparative study of the morphology and histology of the scales of Latimeria menadoensis and $L$. chalumnae (Sarcopterygii: Actinistia, Coelacanthidae) bring new insight on the taxonomy and the biogeography of recent coelacanthids? Pp. 351-360 in Cavin, L., Longbottom, A. \& Richter, M. (eds) Fishes and the Break-up of Pangaea. Geological Society, London, Special Publications, 295.

Meunier, F.J, De Mayrinck, D. \& Brito, P.M. 2015a. Presence of plicidentine in the labial teeth of Hoplias aimara (Erythrinidae; Ostariophysi; Teleostei). Acta Zoologica, 96, 174-180.

Meunier, F. J., Mondejar-Fernandez, J., Goussard, F., Clement, G. \& Herbin, M. 2015 b. Presence of plicidentine in the oral teeth of the coelacanth Latimeria chalumnae Smith 1939 (Sarcopterygii; Actinistia). Journal of structural biology, 190 (1), 31-37.

Meunier, F.J., Otero, O.\& Laurin, M. 2018. Histological study of the jaw teeth in the Devonian actinopterygian $†$ Cheirolepis canadensis (Whiteaves). Cybium, 42 (1), 67-74.

Mickle, K. E. 2015. Identification of the bones of the snout in fossil lower actinopterygians a new nomenclature scheme based on characters. Copeia, 103 (4), 838-857.

Miles R. S. 1977. Dipnoan (lungfish) skulls and the relationships of the group: A study based on new species from the Devonian of Australia. Zoological Journal of the Linnean Society, 61, 1-328.

Millot, J. \& Anthony, J. 1958. Anatomie de Latimeria chalumnae. Tome I. Squelette, muscles et formations de soutien. Editions du Centre National de la Recherche Scientifique, Paris, France. 122 pp.

Mondéjar-Fernández, J. 2018. On cosmine: its origins, biology and implications for sarcopterygian interrelationships. Cybium, 42 (1), 41-65.

Mondéjar-Fernández, J. \& Clément G. 2012. Squamation and scale microstructure evolution in the Porolepiformes (Sarcopterygii, Dipnomorpha) based on Heimenia ensis from the Devonian of Spitsbergen. Journal of Vertebrate Paleontology 32 (2), 267-284.

Mondéjar-Fernández, J. \& Janvier, P. 2014. Further evidence for the presence of holoptychiid porolepiforms (Sarcopterygii, Dipnomorpha) from the Frasnian of Colombia. Comptes Rendus Palevol, 13 (7), 587-597. 
Newberry, J.S. 1857. New fossil fishes from the Devonian rocks of Ohio. American Journal of Science, Series 2, 24, 147-149.

Newberry, J. S. 1873. Description of fossil fishes. Geological Survey of Ohio Report, 1(2), 247-355.

Newberry, J.S. 1889. The Paleozoic fishes of North America. United States Geological Survey Monograph, 16, 1-340.

Olive, S., Pradel, A., Martinez-Pérez, C., Janvier, P., Lamsdell, J.C., Gueriau, P., Rabet, N., Duranleau-Gagnon, P., Cardenas-Rozo, A.L., Zapata Ramirez, P.A. \& Botella, H. 2019. New insights into Late Devonian vertebrates and associated fauna from the Cuche Formation (Floresta Massif, Colombia). Journal of Vertebrate Paleontology, p.e1620247.

Orvig, T. 1957. Remarks on the vertebrate fauna of the lower Upper Devonian of Escuminac Bay, P.Q. Canada, with special reference to the porolepiform crossopterygians. Arkiv för Zoologi, 10 (6), 367-426.

Ørvig, T. 1969. Vertebrates from the Wood Bay Group and the position of the EmsianEifelian boundary in the Devonian of Vestspitsbergen. Lethaia, 2, 272-328.

Otto, M. 1999. New finds of vertebrates in the Middle Devonian Brandenberg Group (Sauerland, Northwest Germany). Palaontologische Zeitschrift, 73, 113-131.

Pearson, D. M.\& Westoll, T.S. 1979. The Devonian actinopterygian Cheirolepis Agassiz. Transactions of the Royal Society of Edinburgh, 70, 337-399.

Qiao, T. \& Zhu, M. 2010. Cranial morphology of the Silurian sarcopterygian Guiyu oneiros (Gnathostomata: Osteichthyes). Science China, Earth Sciences, 53, 1836-1848

Qu, Q., Zhu M. \& Wang, W. 2013. Scales and dermal skeletal histology of an early bony fish Psarolepis romeri and their bearing on the evolution of rhombic scales and hard tissues. PLoS ONE, 8, e61485.

Qu, Q., Sanchez, S., Zhu, M., Blom, H. \& Ahlberg, P. 2016. The origin of novel features by changes in developmental mechanisms: ontogeny and three-dimensional microanatomy of polyodontode scales of two early osteichthyans. Biological Reviews, 92 (2), 11891212.

Romer, A. S. 1955. Herpetichthyes, Amphibioidei, Choanichthyes, or Sarcopterygii? Nature, 176, 126.

Schultze, H.-P. 1969. Die Faltenzähne der Rhipidistiden Crossopterygier, der Tetrapoden und der Actinopterygier-gattung Lepisosteus. Palaeontographica Italica, 65, 63-136. 
Schultze, H.-P. 1970. Folded teeth and the monophyletic origin of tetrapods. American Museum Novitates. 2408, 1-10.

Schultze, H.-P. 1973. Crossopterygier mit heterozerker Schwanzflosse aus dem Oberdevon Kanadas, nebst einer Beschreibung von Onychodontida-Resten aus dem Mitteldevon Spaniens und aus dem Karbon der USA. Palaeontographica, Abteilung A, 143, 188208.

Schultze, H.-P. 2008. Nomenclature and homologization of cranial bones in actinopterygians. Pp. 23-48 in Arratia, G., H.-P. Schultze \& M. V. H. Wilson (eds.). Mesozoic Fishes: 4 Homology and Phylogeny. Verlag Dr. Pfeil, München.

Scotese, C. R. 2001. Atlas of Earth History, PALEOMAP Project, Arlington, Texas, 52 pp

Smith, M. M. 1979. SEM of the enamel layer in oral teeth of fossil and extant crossopterygian and dipnoan fishes. Scanning electron microscopy, 2, 483-489.

Smith, M. M. 1989. Distribution and variation in enamel structure in the oral teeth of sarcopterygians: its significance for the evolution of a protoprismatic enamel. Historial Biology, 3, 97-126.

Stensiö, E. A. 1937. - On the Devonian coelacanthids of Germany with special reference to the dermal skeleton. Kungliga Svenska Vetenskapsakademiens Handlingar, Series 3, 16, $1-56$.

Swofford, D. L. 2002. PAUP*. Phylogenetic Analysis Using Parsimony (*and Other Methods). Sinauer Associates, Sunderland, MA, USA.

Thomson, K. S. \& Hahn, K.V. 1968. Growth and form in fossil rhipidistian fishes (Crossopterygii). Journal of Zoology, London, 156, 199-223.

Turner, S. 1993. Palaeozoic microvertebrate biostratigraphy of eastern Gondwana. Pp. 174207 in Long, J. A. (ed.). Palaeozoic Vertebrate Biostratigraphy and Biogeography. Belhaven Press, London.

Turner, S. \& Murphy, M. A. 1988. Early Devonian microfossils from the Simpson Park Range, Eureka County, Nevada. Journal of Paleontology, 62, 959-964.

Turner, S., Basden, A. \& Burrow, C. J. 2000. Devonian vertebrates of Queensland. Courier Forschungsinstitut Senckenberg, 223, 487-522.

Upeniece, I. 1995. New species of Strunius (Sarcopterygii, Onychodontida) from Latvia, Lode quarry (Upper Devonian). Géobios, 19, 281-284.

Vorobyeva, E. I. 1977. Evolutionary modifications of the teeth structure in the Palaeozoic Crossopterygii. Journal of the Paleontological Society of India, 20, 16-20. 
Witzmann, F. 2013. Phylogenetic patterns of character evolution in the hyobranchial apparatus of early tetrapods. Earth and Environmental Science Transactions of the Royal Society of Edinburgh, 104, 145-167.

Woodward, A. S. 1888. Note on a species of Onychodus in the Lower Old Red Sandstone Passage Beds of Ledbury, Hertfordshire. Geological Magazine, 5, 500-501.

Woodward, A. S. 1889. On the occurrence of the Devonian Onychodus in Spitzbergen. Report of the British Association for the Advancement of Science LIX: 584.

Young, G. C. \& Schultze, H.-P. 2005. New osteichthyans (bony fishes) from the Devonian of Central Australia. Mitteilungen aus dem Museum für Naturkunde in Berlin Geowissenschaftliche Reihe, $\mathbf{8}, 13-35$.

Young, G. C., Long, J. A., \& Ritchie, A. 1992. Crossopterygian fishes from the Devonian of Antarctica: Systematics, relationships and biogeographic significance. Records of the Western Australian Museum Supplement, 14, 1-77.

Yu, X.-B. 1998. A new porolepiform-like fish, Psarolepis romeri, gen. et sp. nov. (Sarcopterygii, Osteichthyes) from the Lower Devonian of Yunnan, China. Journal of Vertebrate Paleontology, 18, 261-274

Zhao, W.-J. \& Zhu, M. 2010. Siluro-devonian vertebrate biostratigraphy and biogeography of China. Paleoworld, 19, 4-26.

Zhu, M. \& Janvier, P. 1994. Un Onychodonte (Vertebrata, Sarcopterygii) du Dévonien Inférieur de Chine. Comptes Rendus de l'Académie des Sciences de Paris, 319, 951956.

Zhu, M. \& Schultze H.-P. 1997. The oldest sarcopterygian fish. Lethaia, 30, 293-304.

Zhu, M. \& Schultze H.-P. 2001. Interrelationships of basal osteichthyans. 289-314. In Ahlberg, P. E. (ed.). Major events in vertebrate evolution. Taylor and Francis, London, UK.

Zhu, M. \& Yu, X. 2002. A primitive fish close to the common ancestor of tetrapods and lungfish. Nature, 418, 767-770.

Zhu, M. \& Yu, X. 2004. Lower jaw character transitions among major sarcopteygian groups - a survey based on new materials from Yunnan, China. Pp. 271-286 in Arratia G., M. V. H.Wilson \& Cloutier R. (eds) Recent advances in the origin and early radiation of vertebrates. Verlag Dr. Friedrich Pfeil, München. 
Zhu, M., \& Zhao, W. 2005. An onychodont-like sarcopterygian fish from the Middle Devonian of Yunnan, southwestern China. Journal of Vertebrate Paleontology, 25 (3, Supplement), 134 A.

Zhu, M., Yu, X. \& Ahlberg, P. E. 2001. A primitive sarcopterygian fish with an eyestalk. Nature, 410, 81-84.

Zhu, M., Yu, X. \& Janvier, P. 1999. A primitive fossil fish sheds light on the origin of bony fishes. Nature, 397, 607-610.

Zhu, M., Yu, X., Wang, W., Zhao, W. \& Jia, L. 2006. A primitive fish provides key characters bearing on deep osteichthyan phylogeny. Nature, 441, 77-80.

Zhu, M., Zhao, W., Jia, L. Lu, J., Qiao, J. \& Q. Qu. 2009. The oldest articulated osteichthyan reveals mosaic gnathostome characters. Nature, 458, 469-474.

Zhu, M., Yu, X., Lu, J., Qiao, T., Zhao, W. \& Jia, L. 2012. Earliest known coelacanth skull extends the range of anatomically modern coelacanths to the Early Devonian. Nature Communications, 3,772 . 


\section{FIGURE CAPTIONS}

Figure 1. Geographical and geological context of Selenodus aquesbiae gen. et sp. nov. White star indicates locality. A. Map of Morocco; B. Geology of Southern Morocco around the town of Akka (modified after Aquesbi 1988); C. Paleogeographical reconstruction of the Middle Devonian (late Pragian-Eifelian, 402-380 Ma) (after Golonka, 2000).

Figure 2. Selenodus aquesbiae gen. et sp. nov. assemblage of fossil material and skull reconstruction under X-rays. Tentative reconstruction of left snout and cheek (MCD 143, Holotype), spiracular (MCD 133) (mirror image of the right spiracular), maxilla (MCD 105, MCD 138) (mirror image of the right maxilla), dentary (MCD 224) (mirror image of the right dentary), opercular series (MCD 218, MCD 219), and skull roof (MCD 130a, MCD 131, MCD 132, MCD 133, MCD 221), postemporal (MCD 132) (mirror image of the right postemporal), ceratobranchials (MCD 140, 141). Arrow points anteriorly. Scale bar equals 10 $\mathrm{mm}$.

Figure 3. Selenodus aquesbiae gen. et sp. nov. left snout and cheek (MCD 143, MCD 216). A-D. Photographs of MCD 143 (Holotype) and MCD 216 (sclerotic ossicles) and interpretative drawings in external view $(\mathbf{A}, \mathbf{C})$ and internal view $(\mathbf{B}, \mathbf{D})$. Arrow points anteriorly. Scale bar equals $10 \mathrm{~mm}$.

Abbreviations: a.no, anterior nostril; A.Te, anterior tectal; ioc, infraorbital lateral line canal; je, jugal lateral line canal; Ju, jugal; L.Ro, lateral rostral; La, lacrimal; Na, nasal; orb, orbit; ?ov.Sp, overlapping surface for a putative spiracular; p.no, posterior nostril; P.Te, posterior tectal; po, pores; poc, postorbital lateral line canal; sc.o, sclerotic ossicle; So, supraorbital; soc, supraorbital lateral line canal; Sq, squamosal.

Figure 4. Selenodus aquesbiae gen. et sp. nov. posterior portion of the right maxilla (MCD 138). A-D. Photographs of MCD 138 and interpretative drawings in external view (A,C) and internal view (B,D). Arrow points anteriorly. Scale bar equals $10 \mathrm{~mm}$.

Abbreviations: int.t, internal ridge; p.ca, pulp cavity; p.exp, posterior expansion; po, pores; r.s, replacement socket. 
Figure 5. Selenodus aquesbiae gen. et sp. nov. anterior portion of the right maxilla (MCD 105). A-D. Photographs of MCD 105 and interpretative drawings in external view $(\mathbf{A}, \mathbf{C})$ and internal view (B,D). Arrow points anteriorly. Scale bar equals $10 \mathrm{~mm}$.

Abbreviations: de, denticles; int.t, internal ridge; p.ca, pulp cavity; p.exp, posterior expansion; po, pores; r.s, replacement socket; t.fo, tooth folds; tu, tubercules.

Figure 6. Selenodus aquesbiae gen. et sp. nov. fragment of the left maxilla (MCD 139). A-D. Photographs of MCD 139 and interpretative drawings in external view (A, C) and internal view $(\mathbf{B}, \mathbf{D})$. Arrow points anteriorly. Scale bar equals $10 \mathrm{~mm}$.

Abbreviations: art.Pmx, articulation surface for the premaxilla; de, denticles; p.ca, pulp cavity; po, pores; r.s, replacement socket; tu, tubercules.

Figure 7. Selenodus aquesbiae gen. et sp. nov. left opercular series comprising the opercular (MCD 218) and preopercular (MCD 219), and a putative right spiracular (MCD 133). A-D, E-F. Photographs of MCD 218, 219, 133 and interpretative drawings in external view $(\mathbf{A}, \mathbf{C}, \mathbf{E}, \mathbf{G})$ and internal view (B,D,F,H). Arrow points anteriorly. Scale bar equals $10 \mathrm{~mm}$. Abbreviations: Op, opercular; ?ov.Cl, overlapping surface a putative cleithrum; ov.L.Ext, overlapping surface for the lateral extrascapular; ?ov.Op, overlapping surface for the opercular; ov.Ma, overlapping surface for the maxilla; ?ov.Ta/Ext, overlapping surface a the tabular or a putative extratemporal; ov.Sq, overlapping surface for the squamosal; Pop, preopercular; popc, preopercular lateral line canal; tu, tubercules.

Figure 8. Selenodus aquesbiae gen. et sp. nov. skull roof elements comprising a fragment of the left parietal (MCD 221) (A-D), the left supratemporal (MCD 130a), tabular and lateral extrascapular (MCD 131) (E-H), a fragment of a postparietal (MCD 226) (I-L) and a putative right posttemporal (MCD 132) (M-P). A,C,E,G,I,J,M,N Photographs of MCD 130a, MCD 131, 132, 221 and interpretative drawings in external view $(\mathbf{B}, \mathbf{F}, \mathbf{K}, \mathbf{O})$ and internal view (D,H,L,P). Scale bar equals $10 \mathrm{~mm}$.

Abbreviations: L.Ex, lateral extrascapular; m.co, medial commissure of lateral extrascapular; ?ov.Na, overlapping surface for nasal; ov.L.Ex, overlapping surface for the lateral extrascapular; ov.Pp, overlapping surface for the postparietal; ?ov.Scl, overlapping surface for the supracleithrum; po, pores; poc, postotic lateral line canal; St, supratemporal; stcc, supratemporal commissural lateral line canal; Ta, tabular; tu, tubercules. 
Figure 9. Selenodus aquesbiae gen. et sp. nov. ceratobranchials (MCD 140, right ceratobranchial; MCD 141, left ceratobranchial). A-P. Photographs of MCD 140 (A-D) and MCD 141 (E-H) and interpretative drawings in anterior view (A,E,I,M), medial view $(\mathbf{B}, \mathbf{F}, \mathbf{J}, \mathbf{N})$, lateral view $(\mathbf{C , G}, \mathbf{K}, \mathbf{O})$ and posterior view (D,H,L,P). Scale bar equals $10 \mathrm{~mm}$. Abbreviations: Cb.gr, ceratobranchial groove; po, pores.

Figure 10. Selenodus aquesbiae gen. et sp. nov. posterior portion of right dentary (MCD 224). A-F. Photographs of MCD 224 and interpretative drawings in lateral view (A,D), dorsal view $(\mathbf{B}, \mathbf{E})$ and medial view $(\mathbf{C , F})$. Insets in $\mathbf{B}$ illustrate the occurrence of dentine plications (plicidentine) at the base of broken teeth. Arrow points anteriorly. Scale bar equals $10 \mathrm{~mm}$. Abbreviations: de, denticles; p.ca, pulp cavity; pli, plicidentine; r.s, replacement socket; tu, tubercules.

Figure 11. Selenodus aquesbiae gen. et sp. nov. left prearticular (MCD 223). A-F. Photographs of MCD 223 and interpretative drawings in lingual (buccal) view (A,D), dorsal view $(\mathbf{B}, \mathbf{E})$ and labial (non-buccal) view $(\mathbf{C , F})$. Arrow points anteriorly. Scale bar equals 10 $\mathrm{mm}$.

Abbreviations: a.s.add.m, attachment surface of the adductor muscle; Art.g, groove for the articular; d.cr, dorsal crest; d.fl, dorsal flange; int.pr, internal process; tu, tubercules.

Figure 12. Selenodus aquesbiae gen. et sp. nov. scales and gill rackers (MCD 213) and palatal dental plates (MCD 212). A. Reconstructed scale in external view and scale ornamentation details (MCD 213). B. MEB photographs of isolated gills rackers. C. MEB photographs of palatal dental plate (MCD 212) and detailed insets (C1-2). Black scale bar equals $10 \mathrm{~mm}(\mathbf{A}, \mathbf{B}, \mathbf{C})$ and white scale bar equals $100 \mu \mathrm{m}(\mathbf{A 1 - 3}, \mathbf{C 1 - 2})$.

Figure 13. Selenodus aquesbiae gen. et sp. nov. isolated teeth (MCD 215). A-B. MEB photographs of isolated teeth and detailed insets of enamel striae (A1-B1) and broken tooth base (B2-3). Scale bar equals $1 \mathrm{~mm}(\mathbf{A}, \mathbf{B})$ and $500 \mu \mathrm{m}(\mathbf{A 1}, \mathbf{B 1 - 2})$. and $500 \mu \mathrm{m}(\mathbf{B 3})$.

Figure 14. Selenodus aquesbiae gen. et sp. nov. isolated scale (MCD 137) in cross section. A. Transversal cross section of isolated scale (MCD 137) and detailed insets of two generations 
of superimposed odontodes (A1), a buried odontode from the first generation (A2) and second generation (A3), and the isopedine of the basal layer (A4) in directly transmitted light (left) and polarized light (right) highlighting the plywood-like structure of the collagen plies. Abbreviations: d, dentine; e, enamel; lb, lamellar bone; vb, vascular bone; vc, vascular canal. Scale bar equals $1 \mathrm{~mm}(\mathbf{A})$ and $100 \mu \mathrm{m}(\mathbf{A 1 - 4})$.

Figure 15. Selenodus aquesbiae gen. et sp. nov. isolated scale and dermal bone (MCD 137) in cross section. A. Longitudinal cross section of isolated scale (MCD 137) showing the overlapped area (right) and the odontode-ornamented exposed area (left) and detailed insets of the odontodes from the exposed area (A1) and from the limit between the exposed and overlapped area (A2). B. Transversal cross section of a fragment from an indeterminate dermal bone from the rear of the skull roof and detailed inset (B1). Abbreviations: d, dentine; e, enamel; lb, lamellar bone; vb, vascular bone; vc, vascular canal. Scale bar equals 1 $\mathrm{mm}(\mathbf{A}, \mathbf{B})$ and $100 \mu \mathrm{m}(\mathbf{A 1 - 2}, \mathbf{B 1})$.

Figure 16. Comparison of the dermal skull of various onychodonts A. Grossius aragonensis from the Late Devonian (Frasnian) of Spain (modified after Schultze 1973); B. Onychodus jandemarrai from the Late Devonian (Frasnian) of Australia (after Andrews et al. 2006); C. Selenodus aquesbiae gen et sp. nov. from the Middle Devonian (Eifelian) of Morocco; D. Strunius walteri from the Late Devonian (Frasnian) of Germany (after Jessen 1966). Course of the lateral line canals in grey. Scale bar equals $10 \mathrm{~mm}$.

Abbreviations: A.Te, anterior tectal; Cl, cleithrum; Cla, clavicle; De, dentary; Ext, extratemporal; Gu, gular; Id, infradentary; 'Io’, infraorbital; Ju, jugal; L.Ex, lateral extrascapular; L.Ro, lateral rostral; La, lacrimal; M.Ex, median extrascapular; Ma, maxilla; MPr, median postrostral; Mr, median rostral; Na, nasal; Op, opercular; P.Te, posterior tectal; Pa, parietal; Pp, postparietal; Pmx, premaxilla; Pop, preopercular; Pt, posttemporal; ?Qj, quadratojugal; Ta, tabular; Sbm, submandibular; Scl, supracleithrum; So, supraorbital; Sop, subopercular; Sp, spiracular; Sq, squamosal; St, supratemporal.

Figure 17. Comparison of the dermal skull of various early osteichthyans A. Guiyu oneiros from the Late Silurian (Ludlow) of China (modified after Zhu et al. 2009); B. Cheirolepis tralli from the Middle Devonian (Givetian) of Scotland (modified after Pearson \& Westoll 1979); C. Gavinia syntrips from the Middle Devonian (Givetian) of Australia (after Long 
1999); D. Miguashaia bureaui from the Late Devonian (Frasnian) of Québec (after Cloutier 1996). Course of the lateral line canals in grey. Scale bar equals $10 \mathrm{~mm}$.

Abbreviations: A.Pr, anterior postrostral; Acl, anocleithrum; Ang, angular; Br, branchiostegal rays; Cl, cleithrum; Cla, clavicle; De, dentary; Dhy, dermohyal; Ecl, extracleithrum; Eta, accessory extratemporal; Ext, extratemporal; Gu, gular; Int, intertemporal; Ju, jugal; L.Ex, lateral extrascapular; L.Ro, lateral rostral; La, lacrimal; Lj, lacrimojugal; M.Ex, median extrascapular; Ma, maxilla; MPr, median postrostral; Mr, median rostral; Na, nasal; Op, opercular; Opa, accessory operculum; P.Pr, posterior postrostral; Pa, parietal; Pp, postparietal; Pmx, premaxilla; Pop, preopercular; Pr, postrostral; Pro, preorbital; Pt, posttemporal; Pscl, presupracleithrum; Qj, quadratojugal; Ta, tabular; Scl, supracleithrum; Spl, splenial; So, supraorbital; Sop, subopercular; Sq, squamosal; St, supratemporal.

Figure 18. Comparison of the otoccipital portion of the dermal skull roof of various onychodonts A. Bukkanodus jesseni from the Early Devonian (Pragian) of Australia (after Johanson et al. 2007); B. Strunius walteri from the Late Devonian (Frasnian) of Germany (modified after Jessen 1966); C. Qingmenodus yui from the Early Devonian (Pragian) of China (after Lu et al. 2016a); D. Selenodus aquesbiae gen et sp. nov. from the Middle Devonian (Eifelian) of Morocco; E. Grossius aragonensis from the Late Devonian (Frasnian) of Spain (modified after Schultze 1973); F. Onychodus jandemarrai from the Late Devonian of Australia (after Andrews et al. 2006). Course of the lateral line canals in grey. Scale bar equals $10 \mathrm{~mm}$.

Abbreviations: L.Ex, lateral extrascapular; M.Ex, median extrascapular; potc, postotic lateral line canal; Pp, postparietal; Ta, tabular; $\mathbf{S t}$, supratemporal.

Figure 19. Phylogenetic analysis based on 38 taxa and 342 characters from Lu et al. 2016a. Tree length= 549 steps, Consistency index CI= 0,5046, Homoplasy index HI=0,4954, Retention index RI=0,7486, Rescaled consistency index RC=0,377. Ligulalepis, Dialipina and Actinopterygii defined as out-group. A. Strict consensus of the 980 most parsimonious trees; B. 50\% majority-rule consensus tree of the 980 most parsimonious trees. The paraphyletically retrieved 'Onychodontida' is here considered to include Bukkanodus, Selenodus, Strunius, Qingmenodus, Grossius and Onychodus. 
